\title{
Braincase and endocranial anatomy of two thalattosuchian crocodylomorphs and their relevance in understanding their adaptations to the marine environment
}

\author{
Yanina Herrera ${ }^{\text {Corresp.., }}{ }^{1}$, Juan Martín Leardi ${ }^{2}$, Marta S Fernández ${ }^{1}$ \\ ${ }^{1}$ CONICET. División Paleontología Vertebrados, Unidades de Investigación Anexo Museo, Facultad de Ciencias Naturales y Museo, Universidad Nacional de \\ La Plata, La Plata, Buenos Aires, Argentina \\ 2 CONICET. Instituto de Estudios Andinos "Don Pablo Groeber" (IDEAN), Facultad de Ciencias Exactas y Naturales, Departamento de Ciencias Geológicas, \\ Universidad de Buenos Aires, CABA, Buenos Aires, Argentina \\ Corresponding Author: Yanina Herrera \\ Email address: yaninah@fcnym.unlp.edu.ar
}

Thalattosuchians are a group of Mesozoic crocodylomorphs known from aquatic deposits of the Early Jurassic-Early Cretaceous that comprises two main lineages of almost exclusively marine forms, Teleosauridae and Metriorhynchoidea. Teleosaurids were found in shallow marine, brackish and freshwater deposits, and have been characterized as semiaquatic near-shore forms, whereas metriorhynchids are a lineage of fully pelagic forms, supported by a large set of morphological characters of the skull and postcranial anatomy. Recent contributions on Thalattosuchia have been focused on the study of the endocranial anatomy. This newly available information provides novel evidence to suggest adaptations on the neuroanatomy, senses organs, vasculature, and behavioral evolution of these crocodylomorphs. However, is still not clear if the major morphological differences between teleosaurids and metriorhynchids were also mirrored by changes in the braincase and endocranial anatomy. Based on X-ray CT scanning and digital endocast reconstructions we describe the braincase and endocranial anatomy of two well-preserved specimens of Thalattosuchia, the semiaquatic teleosaurid Steneosaurus bollensis and the pelagic metriorhynchid Cricosaurus araucanensis. We propose that some morphological traits, such as: an enlarged foramen for the internal carotid artery, a carotid foramen ventral to the occipital condyle, a single CN XII foramen, absence of brain flexures, welldeveloped cephalic vascular system, lack of subtympanic foramina and the reduction of the paratympanic sinus system, are distinctive features of Thalattosuchia. It has been previously suggested that the enlarged foramen for the internal carotid artery, the absence of brain flexures, and the hypertrophied cephalic vascular system were synapomorphies of Metriorhynchidae; however, new information revealed that all of these features were already established at the base of Thalattosuchia and might have been exapted later on their evolutionary history. Also, we recognized some differences within 
Thalattosuchia that previously have not been received attention or even were overlooked (e.g. circular/bilobate trigeminal foramen, single/double CN XII foramen, separation of the cranioquadrate canal from the external otic aperture, absence/presence of lateral pharyngeal foramen). The functional significances of these traits are still unclear. Extending the sampling to other Thalattosuchia will help to test the timing of acquisition and distribution of these morphological modifications among the whole lineage. Also comparison with extant marine tetrapods (including physiological information) will be crucial to understand if some (and/or which) of the morphological peculiarities of thalattosuchian braincases are products of directional natural selection resulting in a fully adaptation to a nektonic life style. 
1 Braincase and endocranial anatomy of two thalattosuchian crocodylomorphs and their relevance

2 in understanding their adaptations to the marine environment

3

4 Yanina Herrera ${ }^{1}$, Juan Martin Leardi ${ }^{2}$ and Marta S. Fernández ${ }^{1}$

5

6 CONICET. División Paleontología Vertebrados, Unidades de Investigación Anexo Museo,

7 Facultad de Ciencias Naturales y Museo, Universidad Nacional de La Plata, La Plata, Argentina.

$8 \quad$ 2CONICET, Instituto de Estudios Andinos "Don Pablo Groeber" (IDEAN), Facultad de Ciencias

9 Exactas y Naturales, Departamento de Ciencias Geológicas, Universidad de Buenos Aires,

10 Buenos Aires, Argentina.

11

12

13 Corresponding author: Yanina Herrera ${ }^{1}$

14 Email address: yaninah@fcnym.unlp.edu.ar

15

16

17

18

19

20

21

22

23 


\section{Abstract}

Thalattosuchians are a group of Mesozoic crocodylomorphs known from aquatic deposits of the

Early Jurassic-Early Cretaceous that comprises two main lineages of almost exclusively marine

forms, Teleosauridae and Metriorhynchoidea. Teleosaurids were found in shallow marine,

brackish and freshwater deposits, and have been characterized as semiaquatic near-shore forms, whereas metriorhynchids are a lineage of fully pelagic forms, supported by a large set of morphological characters of the skull and postcranial anatomy. Recent contributions on Thalattosuchia have been focused on the study of the endocranial anatomy. This newly available information provides novel evidence to suggest adaptations in the neuroanatomy, sense organs, vasculature and behavioral evolution of these crocodylomorphs. However, is still not clear if the major morphological differences between teleosaurids and metriorhynchids (e.g. lateral orbits, absence of osteoderms, reduced and paddle-like forelimb, hypocercal tail) were also mirrored by changes in the braincase and endocranial anatomy. Based on X-ray CT scanning and digital endocast reconstructions we describe the braincase and endocranial anatomy of two wellpreserved specimens of Thalattosuchia, the semiaquatic teleosaurid Steneosaurus bollensis and the pelagic metriorhynchid Cricosaurus araucanensis. We propose that some morphological traits, such as: enlarged foramen for the internal carotid artery, carotid foramen ventral to the occipital condyle, absence of brain flexures, well-developed cephalic vascular system, lack of subtympanic foramina and the reduction of the paratympanic sinus system, are distinctive features of Thalattosuchia. It has been previously suggested that the enlarged foramen for the internal carotid artery, the absence of brain flexures, and the hypertrophied cephalic vascular system were synapomorphies of Metriorhynchidae; however, new information revealed that 
47 these features were already established at the base of Thalattosuchia and might have been

48

49

50

51

52

53

54

55

56

57

58

59

60

61

62

63

64

65

66

67

68

69

exapted later on their evolutionary history. Also, we recognized some differences within

Thalattosuchia that previously have not received enough attention or even were overlooked (e.g. circular/bilobate trigeminal foramen, single/double CN XII foramen, separation of the

cranioquadrate canal from the external otic aperture, absence/presence of lateral pharyngeal

foramen). The functional significance of these traits is still unclear. Extending the sampling to

other Thalattosuchia will help to test the timing of acquisition and distribution of these

morphological modifications among the whole lineage. Also comparison with extant marine

tetrapods (including physiological information) will be crucial to understand if some (and/or

which) of the morphological peculiarities of thalattosuchian braincases are products of

directional natural selection resulting in a full adaptation to a nektonic life style.

Introduction

During the Mesozoic, several groups of reptiles displayed secondary adaptations to life in marine environments and some of them were especially successful and thrived as major predators in the sea (e.g. Massare, 1988; Mazin, 2001; Bardet et al., 2014). The most taxonomically diverse groups of Mesozoic marine reptiles are Sauropterygia, Ichthyosauria, Squamata, and Testudinata (Bardet et al., 2014). Remains of thalattosuchian crocodylomorphs are also abundant and taxonomically diverse in the fossil record; however, this group has received less attention in the scientific literature despite being an important component of the marine vertebrate fauna during the Mesozoic era.

Thalattosuchians are known from aquatic deposits of the Early Jurassic through the Early Cretaceous distributed mainly in the Tethys and Pacific oceans, that comprises two main lineages 
70 of almost exclusively marine forms, Teleosauridae and Metriorhynchoidea (e.g. Fraas, 1902;

71 Andrews, 1913; Jouve, 2009; Pol \& Gasparini, 2009; Young et al., 2010; Wilberg, 2015a).

72 Teleosaurids were recovered in shallow marine, brackish and even freshwater deposits and based

73 on their morphology have been characterized as semi-aquatic and near-shore forms (e.g. Hua \&

74 Buffrenil, 1996; Martin et al., 2016; Johnson et al., 2017). On the other hand, Metriorhynchidae

75 are a lineage of fully pelagic forms, with a large set of morphological traits related to a life in an

76 open ocean environment (e.g. Fraas, 1902; Andrews, 1913; Young et al., 2010).

Among thalattosuchians, the body plan of teleosaurids (elongate and tubular snout, high tooth count, dorsally directed orbits) has been considered as analogous to modern gavials (Andrews, 1913; Westphal, 1962). On the other hand, the derived morphological features of Metriorhynchidae (i.e. laterally directed orbits, reduced and paddle-like forelimbs, hypocercal tail, strongly ventrally directed sacral ribs, loss of osteoderms, hypertrophied nasal glands for salt excretion, reduced olfactory bulbs and olfactory nasal region, and probably were bearing live young; e.g. Fraas, 1902; Andrews, 1913; Fernández \& Gasparini, 2008; Young et al., 2010; Herrera, Fernández \& Gasparini, 2013; Herrera et al., 2017) confer a unique and easily recognizable body plan that differs from that of typical crocodylomorphs. These morphological and physiological modifications were key-features for the successful invasion of the marine 87 realm. based on artificial or natural brain endocasts (e.g. Wharton, 2000; Herrera, 2015; Herrera \& Vennari, 2015). Recent contributions on Thalattosuchia have been focused on the study of the braincase and endocranial anatomy of three-dimensional preserved specimens, based on X-ray computed tomography scanning and 3D visualization techniques. This newly available 
93 information provides novel evidence to suggest adaptations of the neuroanatomy, sense organs,

94 vasculature, and behavioral evolution of these crocodylomorphs (see Fernández et al., 2011;

95 Herrera, Fernández \& Gasparini, 2013; Brusatte et al., 2016; Pierce, Williams \& Benson, 2017).

96 However, it is still not clear if the major morphological differences between teleosaurids and

97 metriorhynchids were also mirrored by changes in the braincase and endocranial anatomy.

98 Herein, we describe the braincase and the brain endocast, vasculature, inner ear, and

99 paratympanic pneumatic cavities of two thalattosuchians: the teleosaurid Steneosaurus bollensis

100 (Jaeger, 1828), and the metriorhynchid Cricosaurus araucanensis (Gasparini \& Dellapé, 1976).

101 We used these specimens as a tool to evaluate the disparity in the braincase and endocranial

102 anatomy between teleosaurids and metriorhynchids, as these represent members of the two

103 distinct clades of Thalattosuchia. In this sense, we explore whether peculiarities in the braincase

104 and endocranial structures of metriorhynchids correspond to novel traits of this clade or if they

105 were widespread among thalattosuchians. Finally, the significance of these structures for our

106 understanding of the paleobiology of these marine crocodylomorphs will be evaluated.

107 Materials \& Methods

108

BSPG 1984 I258, referred to Steneosaurus bollensis, was recovered from Toarcian outcrops located in the surroundings of Altdorf (Mittelfranken, Bayern, Germany) and consists

110 of the braincase three-dimensionally preserved with no evidence of post-mortem deformation. It

111 is almost complete except for the most anterior portion of the frontal and the supraoccipital (Figs.

112 1-2). It was X-ray micro-CT scanned in 2015 in a Nanotom Scan, located at the Zoologische

113 Staatsammlung München (Bavaria State Collection of Zoology, Munich, Germany). Dataset

114 consisted of 1,798 slices $(2261 \times 2443 \times 1798$ voxel, $0.043 \mathrm{~mm}$ voxel size $)$. Due to poor

115 preservation of the external sutures, the bones were segmented separately (Fig. 2). 
117 Covunco Member (middle Tithonian) of the Vaca Muerta Fm. exposed at Cerro Lotena

118 (northwestern Patagonia, Argentina), consists of an almost complete three-dimensionally

119 preserved skull. There is no conspicuous evidence of post-mortem deformation except for the

120 slight displacement of the palatines and pterygoids. For the purpose of this contribution we only

121 provide the description of the braincase. MLP 72-IV-7-1 was helically scanned in a X-ray

122 medical CT-scanner in 2007. Data consisted of 471 slices with a pixel size of $0.448 \times 0.448 \mathrm{~mm}$, a

123 slice thickness of $2 \mathrm{~mm}$, a slice increment of $0.999 \mathrm{~mm}$ and they were output from the scanner in

124 DICOM format. We are aware that the low CT resolution precludes reconstructing fine three-

125 dimensional models of most cranial nerves, endosseous labyrinth of the inner ear and some

126 regions of the paratympanic sinus system. New CT scans of other specimens of C. araucanensis

127 will surely be useful to study the internal anatomy with greater detail. However, the general

128 features of the encephalum and the pneumatic cavities can be observed and discussed. The

129 respective CT data files were imported as DICOM files into Materialise Mimics 10.01

130 (Materialise Inc., Leuven, Belgium) for image segmentation and digital reconstruction.

Institutional abbreviations. AMNH, American Museum of Natural History (Fossil Reptiles),

132 New York, United States; BSPG, Bayerische Staatssammlung für Paläontologie und Geologie,

133 Munich, Germany; GPIT, Paläontologische Sammlung der Eberhard Karls Universität

134 Tübingen, Tübingen, Germany; IVPP, Institute of Vertebrate Paleontology and

135 Paleoanthropology, Chinese Academy of Sciences, Beijing, China; LPP, Institut de

136 paléoprimatologie, paléontologie, humaine; évolution et paléoenvironnements Université de

137 Poitiers, Poitiers, France; MACN, Museo Argentino de Ciencias Naturales "Bernardino

138 Rivadavia”, Buenos Aires, Argentina; MB.R., Museum für Naturkunde Humboldt-Universtät, 
139 Berlin, Germany; MDA, Museo del Desierto de Atacama, Antofagasta, Chile; MGHF, Museo

140 Geológico H. Fuenzalida, Universidad Católica del Norte, Antofagasta, Chile; MJCM, Museo

141 de Ciencias Naturales y Antropológicas “Juan Cornelio Moyano”, Mendoza, Argentina; MLP,

142 Museo de La Plata, La Plata, Argentina; MOZ, Museo Provincial de Ciencias Naturales "Prof.

143 Dr. Juan A. Olsacher”, Zapala, Neuquén, Argentina; MPZ, Museo Paleontológico de la

144 Universidad de Zaragoza, Zaragoza, Spain; NHMUK, Natural History Museum, London, U.K.;

145 SMNS, Staatliches Museum für Naturkunde, Stuttgart, Germany; UCMP, University of

146 California Museum of Paleontology, Berkeley, USA.

147 Results

148 Braincase anatomy of Steneosaurus bollensis (BSPG 1984 I258)

149 The frontal, squamosals and supraoccipital are not well preserved or are largely

150 incomplete (Figs. 1-2), and thus we do not include the description of these bones.

151 Parietal. The parietal is a single element, as in derived crocodylomorphs (Sphenosuchus and 152 more derived taxa) and crocodyliforms (Clark et al., 2004; Leardi, Pol \& Clark, 2017). The

153 parietal is partially preserved (Figs. 1A, 2A). It forms part of the dorsal and posterolateral walls 154 of the braincase. Anteriorly, it contacts the frontal through its elongate anterior process; the 155 dorsalmost region of the intertemporal bar is narrow, forming a sagittal crest (Figs. 1A, 2A), as 156 in all thalattosuchians. Anteroventrally the parietal has a broad contact with the laterosphenoid 157 and posteroventrally with the prootic. The parietal forms the posterior region of the intertemporal 158 bar and the medial and posteromedial margins of the supratemporal fenestrae and fossae (Figs. 159 1A, 1C, 2A, 2C). Posteriorly, the "parietal table" (sensu Brusatte et al., 2016), although slightly 160 incomplete in its posterior region, is less anteroposteriorly developed than in Steneosaurus cf. 161 gracilirostris. In BSPG 1984 I258 the anterior end of the "parietal table" is almost at the level of 
162 the posterior margin of the supratemporal fossa and not at the same plane as the laterosphenoid-

163 prootic suture as in Steneosaurus cf. gracilirostris (Brusatte et al., 2016).

164 Prootic. Both prootics are incompletely preserved. It is exposed on the posteromedial region of

165 the supratemporal fossa (Figs. 1A, 1C, 2A, 2C), as in most thalattosuchians and non-

166 crocodyliform crocodylomorphs (Clark, 1986; Leardi, Pol \& Clark, 2017), and has a dorsal

167 contact with the parietal; this suture could not be recognized externally but it is recognizable in

168 the CT data (Fig. 2A, 2C). Anteriorly, the prootic contacts the laterosphenoid, and posteriorly the

169 quadrate. The prootic forms the dorsal, posterior and ventral margins of the circular trigeminal

170 foramen, and the dorsal and posterior margins of the trigeminal fossa (Figs. 1C, 2C). A circular

171 trigeminal foramen is also present in Steneosaurus cf. gracilirostris (NHMUK PV R.33095),

172 Machimosaurus buffetauti (SMNS 91415), and likely in Teleosaurus cadomensis (Jouve, 2009:

173 Fig. 2). In the posterior margin of the trigeminal foramen the prootic is a slender rod that runs

174 dorsally and separates the trigeminal foramen from the middle ear cavity. Ventral to the

175 trigeminal foramen the prootic contacts anteriorly the laterosphenoid and posteriorly the quadrate

176 (Figs. 1C, 2C).

177 Laterosphenoid. Both laterosphenoids are incompletely preserved (Figs. 1C, 2B-2C). They

178 form most of the lateral wall of the braincase, and contact posteriorly the prootic, and anteriorly

179 delimits the exit for the olfactory tract. The laterosphenoid forms the anterior margin of the

180 trigeminal fossa and foramen. The laterosphenoid-prootic suture is located at the level of the

181 anterior margin of the trigeminal foramen, and the laterosphenoid does not participate in the

182 dorsal and ventral margins of this foramen, as it only reaches the anterior border of the

183 trigeminal foramen. The trigeminal fossa is not developed anteriorly, thus the laterosphenoid is

184 not excavated (Figs. 1C, 2C). CT data shows that the laterosphenoid contacts the basisphenoid 
185 on the floor of the endocranial cavity. Level with the ventral margin of the trigeminal foramen, a

186 groove excavates the lateral surface of the laterosphenoid, which is dorsally delimited by a subtle

187 ridge. This groove is interpreted as the osteological correlate of the ophthalmic branch of the

188 trigeminal nerve $\left(\mathrm{CN} \mathrm{V}_{1}\right)$ (Fig. 1C). In thalattosuchians the presence of a ridge on the region

189 where the laterosphenoid-prootic suture is located has been previously recognized as a unique

190 trait (Holliday \& Witmer, 2009; Fernández et al., 2011), however in this specimen the ridge is

191 not conspicuous and not tightly in contact with the prootic as in other thalattosuchians.

192 Quadrate. Both quadrates are incompletely preserved, with the right one more complete than the

193 left, and only missing the distal ends of the condyles for the articular (Fig. 1). The ventral aspect

194 of the left quadrate is eroded exposing a concave surface that corresponds to the middle ear

195 cavity. The quadrate contacts dorsomedially the prootic and ventromedially the basisphenoid and

196 the pterygoid (Figs. 1B-1C, 2B-2C). The right orbital process of the quadrate is partially

197 covered by sediment and the left one is not preserved (Fig. 1C), however it appears to not be

198 firmly sutured to the braincase, as in other thalattosuchians (Machimosaurus buffetauti, SMNS

199 91415; Jouve, 2009; Holliday \& Witmer, 2009; Fernández et al., 2011; Herrera, Gasparini \&

200 Fernández, 2015; Wilberg, 2015a). The trigeminal fossa is developed posterior to the trigeminal

201 foramen and excavates the anterolateral surface of the quadrate (Figs. 1C, 2C), like in

202 Steneosaurus pictaviensis (LPP.M.37), Machimosaurus buffetauti (SMNS 91415), Cricosaurus

203 araucanensis (MLP 72-IV-7-1), and "Metriorhynchus" cf. westermanni (Fernández et al., 2011).

204 The extension of the fossa in BSPG 1984 I258, posterior to the trigeminal foramen, is probably

205 exaggerated because this region is damaged. The quadrate does not participate in the margin of

206 the trigeminal foramen (Fig.2C). In ventral view, the quadrate contacts the basisphenoid through

207 a serrated suture (Fig. 1B). The quadrate does not reach the basal tuberosities of the basioccipital 
208 (Figs. 1B, 2B), unlike in Steneosaurus cf. gracilirostris (Brusatte et al., 2016), and Pelagosaurus 209 typus (BSPG 1890 I5, NHMUK PV R.32599). In BSPG 1984 I258 the main body of the quadrate

210 has a more lateral direction in comparison with other thalattosuchians and forms an angle of

211 about $70^{\circ}$ with the sagittal plane of the skull (Fig. 1B), similar to Steneosaurus edwarsi

212 (NHMUK PV R.3701). In other thalattosuchians (e.g. Steneosaurus cf. gracilirostris, NHMUK

213 PV R.33095; Pelagosaurus typus, BSPG 1890 I5, NHMUK PV R.32599; Peipehsuchus

214 teleorhinus, IVPP V 10098; Cricosaurus araucanensis, MLP 72-IV-7-1) this angle is more acute

215 and results in the quadrate's body being more posterolaterally directed. On the ventral surface of

216 the quadrate "crest B" (Iordansky, 1973) marks the origin of the M. adductor mandibulae

217 posterior as in most crocodyliforms (Figs. 1B, 2B). In BSPG 1984 I258 "crest B" is sharp and

218 has its medialmost branch posteriorly curved, and it delimits a conspicuous fossa on the ventral

219 surface of the quadrate within the adductor chamber, as in Steneosaurus edwarsi (NHMUK PV

220 R.3701). A well-developed "crest B" has also been described in other thalattosuchians (Jouve,

221 2009; Holliday \& Witmer, 2009; Fernández et al., 2011; Young et al., 2012; Herrera, Gasparini

222 \& Fernández, 2015; Brusatte et al., 2016). Due to preservation, the sutures with the otoccipital,

223 and the region of the cranioquadrate foramen could not be described.

224 Otoccipitals. The exoccipitals and opisthotics are fused in a single element, the otoccipital

225 (Clark, 1986). Both otoccipitals are incomplete, not well preserved and partially reconstructed

226 (Figs. 1D, 2D). The otoccipital forms the lateral margins of the foramen magnum, but it is not

227 possible to determine if it has some degree of participation in the dorsal margin. The foramen

228 magnum is oval, with the major axis mediolaterally oriented. Also, the otoccipital participates in

229 the dorsolateral region of the occipital condyle contacting the basioccipital, as in most

230 crocodylomorphs igs. 1D, 2D. The right paroccipital process is almost complete and is slightly 
231 dorsally directed (Figs. 1D, 2D). The ventrolateral flange of the otoccipital contacts the quadrate

232 in the ventral margin of the occipital surface of the skull, lateral to the lateral pharyngeal

233 foramen. The otoccipital forms approximately half of the posterior margin of the lateral

234 pharyngeal foramen (Figs. 1B, 2B). Lateral to the foramen magnum and at the same level with

235 its ventral margin, the single foramen for the passage of the cranial nerve XII (i.e. hypoglossal

236 foramen) is present (Figs. 1E, 2E), like in Cricosaurus araucanensis (MLP 72-IV-7-1),

237 Teleosaurus cadomensis (Jouve, 2009), "Metriorhynchus" cf. westermanni (Fernández et al.,

238 2011: Fig. 1C) and Steneosaurus cf. gracilirostris (Brusatte et al., 2016), among others, and

239 unlike Pelagosaurus typus (BSPG 1890 I5), the metriorhynchid specimen LPP.M 23 and likely

240 Metriorhynchus brachyrhynchus (LPP.M.22), where the CN XII has two foramina on the

241 occipital surface. Approximately at the same level, on the ventrolateral region of the paroccipital

242 process and lateral to the hypoglossal foramen, there is a large foramen. In BSPG 1984 I258 this

243 foramen is interpreted as the common passage of the cranial nerves IX, X, XI and associated

244 vessels (i.e. metotic foramen), as in Purranisaurus potens (MJCM PV 2060). It is smaller than

245 the internal carotid artery foramen, which is conspicuous in this specimen (Figs. 1D, 2D), as in

246 other thalattosuchians. An enlarged foramen for the internal carotid artery was previously

247 proposed as a synapomorphy of Metriorhynchidae (Pol \& Gasparini, 2009). However, a large or

248 wide internal carotid foramen is also present in the metriorhynchoids Pelagosaurus typus (e.g.

249 BSPG 1890 I5), and Zoneait nargorum (Wilberg, 2015a), and in teleosaurid specimens (e.g. $S$.

250 pictaviensis, LPP.M.37; ?Steneosaurus sp., SMNS 59558; Jouve, 2009), as mentioned by

251 Brusatte et al. (2016). The internal carotid artery foramen in BSPG 1984 I258 is situated

252 ventrally in the occipital surface, lateral to the basioccipital tuberosities and piercing the

253 otoccipital in a posteroventral direction (Figs. 1D, 2D). A posteroventral or ventrolateral 
254 direction of the internal carotid artery foramen is also present in S. bollensis (SMNS 59558), $S$.

255 pictaviensis (LPP.M.37), S. leedsi (NHMUK PV R.3320), S. larteti (GPIT 07283), M. buffetauti

256 (SMNS 91415), T. cadomensis (Jouve, 2009), and differing from the condition in

257 metriorhynchoids, in which the foramen has a strictly posterior direction being only visible in

258 occipital view (see below). Indeed, in some teleosaurid specimens this foramen is only exposed

259 in ventral view (e.g. S. leedsi, NHMUK PV R.3320; Peipehsuchus teleorhinus, IVPP V 10098;

260 M. buffetauti, SMNS 91415).

261 Basioccipital. It forms most of the occipital condyle because the otoccipital participates solely

262 on the dorsolateral region of the condyle, as in Pelagosaurus typus (BSPG 1890 I5), $T$.

263 cadomensis (Jouve, 2009), S. cf. gracilirostris (Brusatte et al., 2016), and the metriorhynchid

264 specimen from Mörnsheim Formation (BSPG 1973 I195), among others. It forms part of the

265 ventral margin of the foramen magnum. In occipital view, the basioccipital is sutured

266 dorsolaterally and laterally to the otoccipital (Figs. 1D, 2D). In ventral view, the basioccipital

267 contacts anteriorly the basisphenoid. The basioccipital forms most of the basioccipital

268 tuberosities, with its posterolateral region located more dorsally than its medial region. On the

269 anteromedial surface of the tuberosities, it is sutured to the basisphenoid. Between the

270 tuberosities this bone forms the posterior margin of the median pharyngeal foramen. Also, the

271 basioccipital forms roughly half of the posterior margin of the lateral pharyngeal foramen (Figs.

$2721 \mathrm{~B}, 2 \mathrm{~B})$.

273 Basisphenoid. The basisphenoid is widely exposed in ventral view. Anteriorly it contacts the

274 pterygoids through a "V"-shaped suture with the apex anteriorly directed, the quadrates laterally,

275 and posteriorly the basioccipital, forming the anterior and lateral margins of the median

276 pharyngeal foramen. The anteroventral surface of the basisphenoid bears two anteroposteriorly 
277 directed crests separated by a concave surface. This anteroventral surface is wider than the

278 median pharyngeal foramen (Figs. 1B, 2B), a similar condition as the one present in S. bollensis

279 (SMNS 15951b, SMNS 15816). The basisphenoid has two posterolateral processes that form the

280 anterior margin of the lateral pharyngeal foramen; these processes contact laterally the quadrates

281 through a serrated suture (Fig. 1B). The presence of the lateral pharyngeal (Eustachian) foramina

282 in S. bollensis is shared with other teleosaurids (e.g. Peipehsuchus teleorhinus, IVPP V 10098; S.

283 pictaviensis, LPP.M.37; T. cadomensis, Jouve, 2009) and basal metriorhynchoids (Pelagosaurus

284 typus, BSPG 1890 I5; Dufeau, 2011: Fig. 1-6C, D; Pierce, Williams \& Benson, 2017). However, 285 this contrast with the condition of most metriorhynchids (e.g. C. araucanensis; the

286 metriorhynchid specimen from Mörnsheim Formation, BSPG 1973 I195; Purranisaurus potens,

287 MJCM PV 2060; Metriorhynchus superciliosus, SMNS 10116; "Metriorhynchus" westermanni,

288 MDA 1) where the lateral pharyngeal foramina are absent. CT data shows that anteriorly, the

289 basisphenoid is sutured dorsally to the laterosphenoid, enclosing the pituitary fossa. On the floor

290 of the endocranial cavity, the internal foramina for the passage of the CN VI were recognized.

291 The canals of these cranial nerves are directed anteroventrally, entering the pituitary fossa dorsal

292 to the internal carotid artery.

293 Endocranial anatomy of Steneosaurus bollensis (BSPG 1984 I258)

294 Morphology of the brain endocast. The endocast of the BSPG 1984 I258 comprises the

295 posterior region of the forebrain to the medulla oblongata, lacking the anterior portion of the

296 olfactory tract. Poor preservation of the bones surrounding the brain ventrally resulted in an

297 incomplete reconstruction of the anterior region of the pituitary fossa and of the anteroventral

298 region of the brain (Fig. 3). 

midbrain-hindbrain flexures not well marked (Fig. 3A-3B). This feature is also present in other

301

thalattosuchians (Fernández et al., 2011; Herrera, 2015; Herrera \& Vennari, 2015; Brusatte et al., 2016; Pierce, Williams \& Benson, 2017). The lateral projection of the bulbous cerebral

hemispheres (at the level of the maximum width of cerebrum) is less extended (Fig. 3C-3D) in comparison with other thalattosuchians (see below) and extant crocodiles (Witmer et al., 2008: Fig. 6.3B; Bona \& Paulina Carabajal, 2013: Fig. 6E; Bona, Paulina Carabajal \& Gasparini, 2017: Fig. 7A). Although preservation precludes the full reconstruction of the pituitary fossa, its general shape and orientation are discernible (Fig. 3A). The pituitary fossa is anteroposteriorly elongated, as in other thalattosuchians (Brusatte et al., 2016; Pierce, Williams \& Benson, 2017) while it contrasts with the rather anteroposteriory shorter pituitary fossa of other crocodyliforms (e.g. Gavialis gangeticus, Pierce, Williams \& Benson, 2017; Simosuchus clarki, Kley et al., 2010; Sebecus icaeorhinus, Colbert, 1946a). As in most crocodyliforms, the pituitary fossa in BSPG 1984 I258 is posteroventrally projected, having its anterior region more dorsally positioned than its posterior one. Posteriorly, the extension of the pituitary fossa reaches the level of the posterior margin of the trigeminal foramen (Fig. 3A).

Vascular elements. The rostral and caudal middle cerebral veins and the internal carotid artery were identified. The rostral middle cerebral vein forms a swelling on the dorsal region of the endocast, posteriorly to the cerebral hemispheres and dorsally to the trigeminal nerve (CN V) (Fig. 3B). The rostral middle cerebral vein exits the braincase through the trigeminal foramen (Fig. 3B, 3D), as in other thalattosuchians. The dorsal longitudinal sinus, that overlays the brain (Fig. 3D), is not as ridge-like as in C. araucanensis (see below), because the dorsal portion of the endocast is flat (Fig. 3A-3B). Posterodorsally on the endocast, the roots of the caudal middle 
322 cerebral vein were reconstructed. These veins are dorsolaterally projected and then turn laterally,

323 within the temporal canal, towards the cranioquadrate canal (Fig. 3A, 3D). These structures were

324 previously recognized in other thalattosuchians and identified as related to vascular elements

325 under different names: portion of the dorsal venous sinus system (Wharton, 2000), "cavity 1"

326 (Fernández et al., 2011), posterior portion of the transverse sinus/posterior middle cerebral vein

327 (Brusatte et al., 2016); or branches of the dorsal longitudinal sinus (Pierce, Williams \& Benson,

328 2017). Due to poor preservation, the distal part of this vascular canal (temporal canal) its

329 relationship with the cranioquadrate canal cannot be traced with confidence. However, the

330 preserved morphology is consistent with those of other thalattosuchians, and the lateral

331 projection of the preserved temporal canal suggests that both structures are confluent (Fig. 3G).

332 The carotid canals run from the ventral region of the occipital surface of the skull to the

333 pituitary fossa (Fig. 3B, 3F). The most posterior portion runs parallel to the midline of the skull

334 for a short way (this portion is shorter than in C. araucanensis, see below), to turn obliquely

335 afterwards. In BSPG 1984 I258 the longest part of the carotid canal is directed from

336 posterolaterally to anteromedially (Fig. 3F). The carotid canals enter the pituitary fossa piercing

337 its posterior wall through two separate foramina. The carotid canals are not completely ossified,

338 thus the middle portion of the canal could not be segmented separately from the

339 pharyngotympanic sinus (Fig. 3B, 3D, 3F). A similar condition has been recognized in $S$. cf.

340 gracilirostris (Brusatte et al., 2016) and other extinct crocodylomorphs and extant crocodilians

341 (e.g. Sedlmayr, 2002; Bona, Degrange \& Fernández, 2013; Dufeau \& Witmer, 2015).

342 Nerves. Canals of the III, V, VI, VII, IX-XI, and XII cranial nerves were recognized and

343 reconstructed. As we mentioned above, the anteroventral region of the braincase of BSPG 1984

344 I258 is damaged in a way that some of the nerves that originate from the ventrolateral region of 
345 the midbrain could not be identified.

346 On the lateral wall of the braincase, ventrolaterally to the cerebral hemispheres, the

347 foramen that pierces the laterosphenoid is here interpreted as the foramen for the oculomotor

348 nerve (CN III) (Fig. 3B, 3F). The large trigeminal foramen which contains the trigeminal

349 ganglion $(\mathrm{Vg})$ is identified as it is ventrolaterally projected from the endocast (Fig. 3B, 3D, 3F).

350 Cranial nerve VI (abducens) exits the endocranial cavity through the basisphenoid via

351 individual foramina, posteroventrally to $\mathrm{CN} \mathrm{V}$ (Fig. 3B, 3F). Two passages for the branches of

352 CN VI project slightly anteroventrally from the ventral side of the hindbrain and pass laterally to 353 the pituitary fossa (Fig. 3B). A small canal posterior to the trigeminal nerve (CN V) foramen is

354 identified as the facial nerve canal (CN VII) which exits the endocranial cavity through a

355 foramen in the prootic (Fig. 3B). Cranial nerves IX, X, XI, and XII originate from the lateral

356 region of the hindbrain. Cranial nerves IX, X, XI exit the endocranial cavity through a

357 dorsoventrally elongated metotic foramen. Posteriorly, cranial nerve XII (hypoglossal) has a

358 single root on the endocast and only one external opening in the posterior surface (Fig. 3B, 3D,

$3593 \mathrm{~F}, 3 \mathrm{H})$.

360 Paratympanic sinus system. In BSPG 1984 I258 several interconnected diverticular expansions

361 from both the pharyngotympanic sinus and median pharyngeal sinus (sensu Dufeau \& Witmer,

362 2015) have been identified (Fig. 3A, 3C, 3E, 3G). As the condition present in most

363 crocodyliforms (e.g. Protosuchus richardsoni, Notosuchus terrestris, Caiman latirrostris), the

364 paratympanic sinus system of $S$. bollensis communicates with the pharynx via a single medial

365 foramen (median pharyngeal foramen), and two lateral foramina (lateral pharyngeal foramina).

366 The median pharyngeal tube (= median Eustachian tube) bifurcates in two paired system

367 of pneumatic canals, an anterior pair and a posterior pair (anterior and posterior communicating 
368 canals, sensu Miall, 1878). The posterior communicating canals diverge almost at 90 degrees

369 from the median canal. They are then directed laterally and dorsally and connect with the middle

370 ear cavity. The posterior communicating canals bear some expansions on their path to contribute

371 to the pneumatization of the posterior part of the basioccipital (basioccipital diverticulum sensu

372 Dufeau \& Witmer, 2015) (Fig. 3E, 3G). The anterior communicating canals are connected to the

373 median pharyngeal tube through a wide anteroposteriorly directed tube that runs through the

374 ventral surface of the basisphenoid (anterodorsal branch of the basisphenoid diverticulum) (Fig.

$3753 \mathrm{~A}, 3 \mathrm{E})$. The anteriormost part of the ventral canal is expanded, in the same region where the

376 two dorsolaterally directed anterior communicating canals originate. At this point a slight ventral

377 projection of the anterior communicating canals is seen, however it is difficult to evaluate if this

378 pneumatization continues into the pterygoids, forming a pterygoid diverticulum (Fig. 3A, 3E,

$3793 \mathrm{G})$. The anterior communicating canals are much broader than the posterior ones, and after a

380 short dorsoventral extension, enter the middle ear cavity on its anteroventral region (Fig. 3E).

381 The middle ear cavity is mediolaterally elongated and tubular, due to the particular

382 thalattosuchian condition where the quadrate extends its limit well laterally when compared to

383 other crocodyliforms. The quadrate lacks any well-developed additional pneumatization (Fig.

384 3A, 3C, 3E, 3G). That is, BSPG 1984 I258 lacks any infundibular diverticulum, like

385 Pelagosaurus typus (Dufeau, 2011), S. cf. gracilirostris (contra Brusatte et al., 2016; see below),

386 and C. araucanensis (see below). In derived crocodylomorphs (i.e. Macelognathus) and most

387 crocodyliforms (e.g. Protosuchus richardsoni, Notosuchus terrestris, Caiman latirostris) the

388 quadrate is heavily pneumatized, both anterior to the otic aperture (infundibular diverticulum)

389 and on the distal body of the quadrate (quadrate diverticulum). These pneumatizations

390 communicate with the middle ear cavity and also have an independent external opening through 
391 one subtympanic foramen (or quadrate fenestra) (e.g. Macelognathus, C. latirostris) or multiple

392 (e.g. Junggarsuchus, P. richardsoni, Notosuchus) (Leardi, Pol \& Clark, 2017). Thus, the

393 subtympanic foramina are the external osteological correlates of these quadrate pneumatizations

394 (Dufeau \& Witmer, 2015). Furthermore, no thalattosuchian with the presence of a subtympanic

395 foramen has been reported (e.g. C. araucanensis, S. bollensis, Dakosaurus, Pelagosaurus,

396 Teleosaurus), reinforcing the interpretation of the lack of quadrate pneumatization in

397 thalattosuchians. In other recent contributions, the infundibular diverticulum has been identified

398 in the teleosaurid S. cf. gracilirostris (Brusatte et al., 2016), however this specimen does not

399 have any individualized pneumatization that invades the quadrate anteriorly to the otic aperture,

400 and what was identified as the pneumatic inflations of the suspensorium are not separated from

401 the middle ear cavity. The posterior part of the middle ear cavity of BSPG 1984 I258 bears a

402 posterior sheet-like expansion, just at the level where the posterior communicating canal enters

403 the middle ear (Fig. 3G). This posterior laminar expansion slightly pneumatizes the pterygoid

404 process of the quadrate, but it never reaches the distal body of the quadrate, thus not forming a

405 proper quadrate diverticulum (sensu Dufeau \& Witmer, 2015). This condition is shared with

406 other thalattosuchians, as the absence of a quadrate diverticulum was described previously for $P$.

407 typus (Dufeau, 2011) and S. cf. gracilirostris (Brusatte et al., 2016).

408 Anterodorsally, the paratympanic cavity of BSPG 1984 I258 is convex and slightly

409 projected, and as a result the posteroventral surface of the prootic is concave. A similar

410 morphology has been identified for S. cf. gracilirostris and P. typus, which lead to the

411 identification of this dorsal projection of the paratympanic cavity as the prootic diverticulum

412 (Brusatte et al., 2016; Pierce, Williams \& Benson, 2017). However, in modern crocodylians the

413 prootic diverticulum is positioned at the level of the semicircular canals, just anterior to them, 
414 and dorsal to the trigeminal ganglion (Vg), forming an isolated pneumatic recess (Dufeau \&

415 Witmer, 2015). None of the features mentioned before can be observed in the CT data of any of

416 the thalattosuchians examined to date. Thus, a well-developed prootic diverticulum seems to be

417 absent in thalattosuchians.

418 On the other hand, the middle ear cavity has a convex profile in lateral view and, unlike 419 derived non-crocodyliform crocodylomorphs (Kayentasuchus, Dibothrosuchus, Junggarsuchus, 420 Macelognathus) and most crocodyliforms (e.g. Protosuchus richardsoni, Caiman latirostris), it 421 does not invade the prootic. In derived crocodylomorphs a pneumatic cavity has been described 422 in the posterodorsal region of the prootic, usually referred as the mastoid antrum. In 423 crocodyliforms this sinus (intertympanic sinus, sensu Dufeau \& Witmer, 2015) penetrates into 424 the supraoccipital and passes through it, connecting the middle ear and paratympanic 425 pneumatizations from both sides (Clark, 1986). This feature is not present in S. bollensis nor in 426 other thalattosuchians where CT data has been made available (Brusatte et al., 2016; Pierce, 427 Williams \& Benson, 2017) or where natural breakage of the supraoccipital has allowed 428 observation of this feature (Wilberg, 2015b).

429 Finally, in BSPG 1984 I258 the pharyngotympanic sinus is expanded posteriorly, 430 partially pneumatizing the otoccipital. The posterior sheet-like expansion of the middle ear 431 cavity mentioned above, before entering the quadrate, expands as it enters the ventral part of the 432 otoccipital (Fig. 3A, 3C, 3E, 3G). The dorsal region of the otoccipital is also pneumatized by a 433 posterior rounded evagination of the pharyngotympanic sinus. However, this pneumatization is 434 restricted to the ventral part of the otoccipital. A similar condition has been reported in other 435 thalattosuchians (Dufeau, 2011: Fig. 1-6C, 1-6D; Brusatte et al., 2016; Pierce, Williams \& 436 Benson, 2017). 
437 Endosseous labyrinth of the inner ear. The general aspect of the endosseous labyrinth in 438 BSPG 1984 I258 is similar in shape to that of extant and extinct crocodilians (Fig. 4), i.e. a

439 triangular vestibular apparatus dorsally and an elongated cochlea ventrally (e.g. Witmer et al., 440 2008; Bona, Degrange \& Fernández, 2013; Pierce, Williams \& Benson, 2017). The anterior

441 semicircular canal is slightly longer than the posterior one, which is similar to the lateral canal

442 (Fig. 4B, 4D). The cochlear ducts extend largely ventrally, with only a slight medial component

443 (Fig. 4A, 4C). In BSPG 1984 I258, the complete inner ear is approximately $20.5 \mathrm{~mm}$ tall and has

444 a maximum width of $16 \mathrm{~mm}$ at the level of the semicircular canals.

445

446

447

448

449

450

451

452

453

454

455

456

457

458

459

\section{Braincase anatomy of Cricosaurus araucanensis (MLP 72-IV-7-1)}

Frontal. The frontal is completely fused. The postorbital processes form an acute angle of about $45^{\circ}$ with the midline of the skull. The anteromedial process of the frontal wedges anteriorly

between the posteromedial processes of the nasal and extends further anteriorly than the level of the posterior margin of the preorbital fossa. The frontal has a reduced participation in the dorsal margin of the orbit (Fig. 5A). Posterolaterally, the frontal contacts the postorbital trough a V-

shaped suture with the apex pointed posteriorly. The postorbital process of the frontal forms the posterodorsal margin of the orbit, and the anteromedial margin of the supratemporal fossa. The frontal extends posteroventrally and forms most of the anterior floor of the supratemporal fossa. In ventral view the frontal contacts anteriorly with the prefrontal, and posteroventrally, with the laterosphenoid forming the exit for the olfactory tract. The groove on the skull roof is the osteological correlate of the olfactory tract and is delimited laterally by two low crista cranii. The anterior portion of the groove is mediolaterally wider than the posterior one.

Parietal. The parietal is a "T"-shaped element with an anterior (frontal) process and two lateral (squamosal) processes (Fig. 5A). The anterior process forms the posterior region of the 
460 intertemporal bar and contacts the frontal; the lateral process is sutured to the squamosal, both

461 via serrated sutures (Figs. 5A, 6A). Posterodorsally, the parietal bears a large posterior notch

462 between the squamosal processes, forming a semicircular or "U"-shaped structure in dorsal view

463 (Fig. 5A, 5C). This posterior parietal notch is also present in other metriorhynchids such as:

464 Cricosaurus lithographicus (MOZ-PV 5787), Cricosaurus elegans (BSPG AS I 504),

465 Metriorhynchus brachyrhynchus (LPP.B.1), and the metriorhynchid specimen from the

466 Mörnsheim Formation (BSPG 1973 I195). The parietal is well-extended posteriorly, having

467 participation in the central region of the occipital surface. Given this condition, the supraoccipital

468 is excluded from the dorsal aspect of the skull (Fig. 5C) as in most non-eusuchian and non-

469 notosuchian crocodyliforms (Clark, 1986).

470 In occipital view the parietal is ventrally sutured to the supraoccipital and ventrolaterally

471 has a reduced contact with the otoccipital near the midline. In the place where the parietal

472 contacts the otoccipital and the supraoccipital, there is a reduced and obliterated fossa, which

473 corresponds topographically to where the posttemporal fenestra is located in other

474 crocodylomorphs. The lateral processes of the parietal develop a rim over the occipital surface,

475 which continues in the squamosal (Fig. 5C).

476 Within the supratemporal fossa, the parietal is projected ventrally, forming part of the

477 posterolateral wall of the braincase as well the medial margin of the supratemporal fenestra

478 (Figs. 5A, 6A). Within the fossa, the parietal is anteriorly sutured to the frontal through a

479 transverse and interdigitated suture, anteroventrally to the laterosphenoid, and posteroventrally to 480 the prootic. The parietal forms the dorsomedial margin of the temporo-orbital foramen (Fig. 6A).

481 Squamosal. The squamosal contributes to the posterior and posterolateral margins of the

482 supratemporal fossa and fenestra. The squamosal participation in the supratemporal arch is 
483 reduced, with the postorbital contributing around $75 \%$ of the arch. Anterolaterally the squamosal

484 contacts the postorbital, while posteromedially it contacts the parietal (Fig. 5A). The squamosal-

485 postorbital suture is serrated on the lateral aspect of the skull, and within the supratemporal fossa

486 the suture is straight and "V"-shaped with the apex oriented anteriorly. In dorsal view the

487 squamosal is narrow and slightly concave (Fig. 5A). Within the supratemporal fossa the

488 squamosal extends ventrally contacting the quadrate and the prootic (Fig. 6A). The suture with

489 the latter is given by the ventral branch of the dorsomedial process of the squamosal, which is

490 broader than the dorsal one. The squamosal forms the dorsolateral margin of the reduced

491 temporo-orbital foramen (Fig. 6A).

492

In occipital view the squamosal is sutured to the dorsolateral margin of the paroccipital

493 process via a rounded posterior process (Fig. 5C). Visible in lateral and posterior views is the

494 smooth and slightly concave subcircular structure of the squamosal present in other

495 thalattosuchians (e.g. S. leedsi, NHMUK PV R.3320; D. andiniensis, MOZ-PV 6146; C.

496 lithographicus, MOZ-PV 5787; Maledictosuchus riclaensis, MPZ 2001/130a; Torvoneustes

497 coryphaeus, Young et al. 2013; Tyrannoneustes lythrodectikos, Foffa \& Young, 2014).

498 Prootic. The prootic is broadly exposed on the lateral wall of the braincase and it is exposed on

499 the posteromedial margin of the supratemporal fossa (Fig. 5A), as in non-crocodyliform

500 crocodylomorphs and other thalattosuchians (Leardi, Pol \& Clark, 2017). This bone has a

501 subpentagonal shape and contacts anteriorly the laterosphenoid, dorsally the parietal, posteriorly

502 the squamosal, and ventrally the quadrate (Fig. 6A). The prootic forms the ventral margin of the

503 temporo-orbital foramen (Fig. 6A), as in Pelagosaurus typus (NHMUK PV R.32599),

504 Teleosaurus cadomensis (Jouve, 2009) and Purranisaurus potens (MJCM PV 2060). In MLP 72-

505 IV-7-1, the prootic has a reduced contribution to the dorsal margin of the trigeminal fossa 
506 (although this feature is variable among the $C$. araucanensis specimens). The prootic forms the

507 posterior half of the bilobate trigeminal foramen (Fig. 6B, 6C).

508 Laterosphenoid. It forms most of the lateral and anteroventral walls of the endocranial cavity,

509 surrounding the cerebral hemispheres. The laterosphenoid forms the anterior margin of the

510 supratemporal fossa. Anterior and dorsally it contacts the frontal and postorbital (Fig. 5A).

511 Within the supratemporal fossa, the laterosphenoid has a broad dorsal contact with the parietal

512 and briefly contacts the frontal. The laterosphenoid is posteriorly sutured to the prootic through a

513 suture that forms a pronounced ridge (Fig. 6A), as in other thalattosuchians (e.g. Purranisaurus

514 potens, MJCM PV 2060; Metriorhynchus superciliosus, SMNS 10116; Pelagosaurus typus,

515 BSPG 1890 I5; Steneosaurus bollensis, SMNS 15951b; Holliday \& Witmer, 2009; Fernández et

516 al., 2011; Brusatte et al., 2016). In ventral view, the anterodorsal region contacts its counterpart

517 and together with the frontal delimits the exit for the olfactory tract. Anteroventral to the

518 trigeminal fossa, the laterosphenoid contacts the pterygoid (Fig. 6B).

519 The laterosphenoid forms the anterior and anteroventral margins of the trigeminal

520 foramen. In MLP 72-IV-7-1 the trigeminal foramen is bilobate-shaped, with a posterodorsal

521 lobule much smaller than the anteroventral one (Fig. 6B), as in "Metriorhynchus" cf.

522 westermanni (MDA 2), Dakosaurus cf. andiniensis (MOZ-PV 089), the metriorhynchid

523 specimen LPP.M.23, and Pelagosaurus typus (NHMUK PV R.32599). The same morphology is

524 observed in the natural casts of the brain of Cricosaurus araucanensis (e.g. MLP 73-II-27-3,

525 MLP 76-II-19-1, MOZ-PV 7261; Herrera, 2015; Herrera \& Vennari, 2015) as two lobules were

526 identified: a small lobule was interpreted as the middle cerebral vein while a large one was

527 assumed to correspond to the trigeminal nerve (CN V). Anterior to the trigeminal foramen the

528 laterosphenoid is slightly excavated, forming a shallow triangular anterior trigeminal fossa (Fig. 
529 6C). This fossa is dorsally delimited by a crest which is interpreted as the osteological correlate

530 of the opthalmic branch of the trigeminal nerve $\left(\mathrm{CN} \mathrm{V}_{1}\right)$, as was identified in "M." cf.

531 westermanni (Fernández et al., 2011) and S. cf. gracilirostris (Brusatte et al., 2016). Dorsal to

532 this crest, there is an anterodorsally directed groove that we interpret as the correlate of the

533 maxillary branch of the trigeminal nerve $\left(\mathrm{CN} \mathrm{V}_{2}\right)$ (Fig. 6C).

534 Anterodorsal to the trigeminal fossa, the left laterosphenoid is eroded leaving exposed the 535 natural cast of the brain, specifically the dorsal region of the cerebral hemispheres. Here, there

536 are two small blood vessel infillings with bone tissue preserved between them (Fig. 6A), as in the

537 dorsal region of the cerebral hemispheres of the metriorhynchids from Vaca Muerta Fm. MOZ-

538 PV 089, MOZ-PV 7201, MOZ-PV 7261 (Herrera, 2015; Herrera \& Vennari, 2015).

539 Quadrate. In MLP 72-IV-7-1 the quadrates are almost completely preserved, lacking only part

540 of the condylar region (Figs. 5B, 6A-6C). Within the supratemporal fossa, the quadrate contacts

541 dorsally the squamosal and medially the prootic. In MLP 72-IV-7-1 the quadrate does not

542 contact the laterosphenoid, as in most thalattosuchians (Clark, 1986), because the prootic is

543 exposed in the supratemporal fossa, thus precluding the contact between these two bones

544 (Leardi, Pol \& Clark, 2017) (Fig. 6A). In MLP 72-IV-7-1 the fossa excavates the quadrate, thus

545 this bone forms the posterior and ventral margins of the trigeminal fossa. The trigeminal fossa is

546 broadly developed posterior to the trigeminal foramen (Fig. 6B-6C), as in most metriorhynchids

547 (e.g. M. brachyrhynchus, LPP.M.22; "M." westermanni and "M." cf. westermanni; Fernández et

548 al., 2011; Plesiosuchus manselli, Young et al., 2012) and some teleosaurids (e.g. Machimosaurus

549 buffetauti, SMNS 91415; S. pictaviensis, LPP.M.37). The quadrate does not participate on the

550 temporo-orbital foramen (Fig. 6A-6B), as in Pelagosaurus typus (BSPG 1890 I5, NHMUK PV

551 R.32599), and unlike the condition present in Teleosaurus cadomensis (Jouve, 2009) and 
552 Machimosaurus buffetauti (SMNS 91415; Martin \& Vincent, 2013), where the quadrate

553 participates very slightly to the ventrolateral margin. The orbital process of the quadrate remains

554 free of bony attachment (Fig. 6B-6C), as in other thalattosuchians.

555 In ventral view, the quadrate contacts the basioccipital and the basisphenoid medially, but 556 due to damage on the holotype specimen (MLP 72-IV-7-1), we cannot describe in detail this

557 region as well as the contact with the pterygoids. "Crest B" of the quadrate is low and wide and it 558 is developed on the anterior border of the quadrate (Fig. 5B). Anterior to "crest B", the quadrate

559 is not exposed (in ventral view), as in "M." cf. westermanni (MDA 2; Fernández et al., 2011: Fig. 560 1B), Purranisaurus potens (MJCM PV 2060), and the metriorhynchid specimen (LPP.M.23).

561 The pterygoid process of the quadrate is broad and it widens anterodorsally, forming an

562 expanded distal end (Fig. 5B).

563 In occipital view, the quadrate contacts the ventrolateral flange of the otoccipital. The 564 quadrate forms the lateral margin of the cranioquadrate canal (Fig. 5C). In MLP 72-IV-7-1, the 565 cranioquadrate foramen and canal are separated from the external otic aperture by a bony lamina 566 (Fig. 5C), as in other metriorhynchids (e.g. Purranisaurus potens, MJCM PV 2060;

567 Maledictosuchus riclaensis, MPZ 2001/130a, Parrilla-Bel et al., 2013; Torvoneustes coryphaeus, 568 Young et al., 2013) and in the teleosaurids ?Steneosaurus sp. (SMNS 59558) and

569 Machimosaurus buffetauti (SMNS 91415). This differs from the condition present in 570 Pelagosaurus typus (BSPG 1890 I5), Steneosaurus pictaviensis (LPP.M.37), and Teleosaurus 571 cadomensis (Jouve, 2009) where these structures are incompletely separated. In C. araucanensis 572 the external otic aperture is located posterior to the infratemporal fenestra and opens

573 ventrolaterally. In lateral view the otic aperture is triangular shaped with rounded corners and is 
574 completely enclosed within the quadrate. The dorsal margin is overhung by the squamosal, but it

575 does not form part of this margin. The quadrate encloses most of the middle ear cavity.

576 Otoccipital. The otoccipital contacts the supraoccipital dorsally, the parietal and squamosal

577 dorsolaterally, and the quadrate ventrolaterally, and forms the dorsal and lateral margins of the

578 foramen magnum. The foramen magnum is oval, with the major axis mediolaterally oriented. We

579 cannot determine if the otoccipital participates in the dorsal region of the condyle because the

580 sutures are not visible (Fig. 5C). However, in MLP 72-IV-7-4 the otoccipitals participate in the

581 dorsolateral part of the occipital condyle as in most crocodylomorphs. In ventral view it is

582 sutured laterally to the quadrate and medially to the basioccipital (Fig. 5B).

583 The paroccipital processes are orientated dorsally (Fig. 5C), as in other metriorhynchids

584 (e.g. "M." casamiquelai, MGHF 1-08573; "M." cf. westermanni, MDA 2; Plesiosuchus manselii,

585 Young et al., 2012; Maledictosuchus riclaensis, Parrilla-Bel et al., 2013; Torvoneustes

586 coryphaeus, Young et al., 2013). Unlike many crocodylomorphs (e.g. Protosuchus richardsoni,

587 UCMP 131827; Notosuchus terrestris, MACN-RN 1037; Steneosaurus bollensis, see above;

588 Caiman yacare, MACN 15145; Almadasuchus figarii, Pol et al., 2013) the paroccipital processes

589 are strongly convex on their medial two thirds, while the lateral third is straight. Laterally, the

590 otoccipital contacts the squamosal, through the distal ends of the paroccipital processes. The

591 paroccipital process forms the medial and dorsal borders of the cranioquadrate passage (Fig. 5C).

592 The ventrolateral flange of the otoccipital is sutured ventrolaterally to the quadrate and

593 ventromedially to the basioccipital. Ventrolateral to the foramen magnum, this region is pierced

594 by several foramina of different diameter. Lateral to the foramen magnum and level with its

595 ventral margin, a small foramen for the passage of CN XII is identified (Fig. 5C). As mentioned

596 above, a single foramen for the exit of CN XII is present in most thalattosuchians. There are 
597 three foramina located ventrolateral to the occipital condyle (Fig. 5C). The two lateralmost

598 foramina are identified as the exit of cranial nerves IX, X, XI and associated vessels (e.g. jugular 599 vein). The medialmost foramen, which is ventral to CN IX, X, XI foramina, is not far from the 600 ventral margin of the basioccipital tuberosities and is identified as the enlarged foramen for the 601 internal carotid artery. This foramen is oriented posteriorly in the occipital surface, a condition 602 also observed in other metriorhynchoids (e.g. Pelagosaurus typus, BSPG 1890 I5; Purranisaurus 603 potens, MJCM PV 2060; Dakosaurus andiniensis, MOZ-PV 6146; "M." cf. westermanni, MDA 2; Plesiosuchus manselii, NHMUK PV R.1089; Torvoneustes coryphaeus, Young et al. 2013; Maledictosuchus riclaensis, MPZ 2001/130a; Tyrannoneustes lythrodectikos, Foffa \& Young, 2014; Zoneait nargorum, Wilberg, 2015a). In some metriorhynchoid specimens a groove or 607 canal associated with the foramen is ventrally directed (e.g. Pelagosaurus typus, BSPG 1890 I5; 608 "M." cf. westermanni, MDA 2; Dakosaurus andiniensis, MOZ-PV 6146; Purranisaurus potens, MJCM PV 2060; and the metriorhynchid specimen LPP.M.23).

Supraoccipital. This bone, exposed solely in occipital view. It is flat and subrhomboidal. The supraoccipital is wider (lateromedially) than tall (dorsoventrally) in posterior view (Fig. 5C), as

612 in Almadasuchus and crocodyliforms (Leardi, Pol \& Clark, 2017). Dorsally it contacts the parietal and ventrolaterally the otoccipital. In MLP 72-IV-7-1 the supraoccipital does not 614 contribute to the dorsal margin of the foramen magnum because of the participation of the 615 otoccipitals (Fig. 5C). However, this feature is variable among C. araucanensis specimens, as in 616 MLP 72-IV-7-2 and MLP 86-XI-5-7 the supraoccipital reaches the border of the foramen 617 magnum. There is a raised rim in the dorsal region of the supraoccipital-otoccipital suture that is 618 interpreted as the occipital tuberosities described by Brusatte et al. (2016) for teleosaurids, 619 although these are less pronounced than previously reported. Medial to these tuberosities there 
620 are also subtle raised rims, aligned with the vertical walls of the "U"-shaped structure of the 621 parietal (Fig. 5C).

622 Basioccipital. The basioccipital forms the occipital condyle and, as mentioned before, we cannot 623 distinguish if the otoccipital participates in the occipital condyle (Fig. 5C). Ventral to the 624 condyle, in occipital view, the exposed surface is dorsoventrally short and anteroventrally 625 oriented (Fig. 5C). The basioccipital tuberosities are incompletely preserved because the external 626 surface is eroded; however they are exposed in posterior and ventral views (Fig. 5B-5C). In 627 ventral view, the basioccipital tuberosities form a wide "U" with the lateral region in contact with 628 the quadrate. It is triangular and between the tuberosities, it forms the posterior and lateral 629 borders of the median pharyngeal foramen (Fig. 5B).

630 Basisphenoid. In MLP 72-IV-7-1 the basisphenoid is broken and poorly preserved. It is exposed 631 in ventral and lateral view. In ventral view, it contacts the basioccipital posteriorly, laterally the 632 quadrate and anteriorly the pterygoid. The basisphenoid forms the anterior margin of the median 633 pharyngeal foramen (Fig. 5B).

634 Endocranial anatomy of Cricosaurus araucanensis (MLP 72-IV-7-1)

635 Morphology of the brain endocast. The cranial endocast of MLP 72-IV-7-1 is complete, from 636 olfactory bulbs to the medulla oblongata and represents approximately $30 \%$ of the skull length. It 637 is approximately $141 \mathrm{~mm}$ long, from the foramen magnum to the olfactory bulbs, and has a 638 maximum width of $26 \mathrm{~mm}$ across the cerebral hemispheres. The brain is elongated, narrow, and 639 relatively straight in lateral view. The dorsal border of the medulla oblongata is almost in the 640 same horizontal plane with the olfactory tract in lateral view, as the midbrain-hindbrain and 641 within hindbrain flexures are not marked (Fig. 7A-7B). This particular trait has already been 
642 noted in previous contributions based on natural brain endocasts (e.g. MLP 76-II-19-1, MOZ-PV

643 7201; Herrera, 2015).

644 The olfactory tract is long and forms approximately half of the total length of the brain 645 endocast, as in most longirostrine crocodylomorphs (Pierce, Williams \& Benson, 2017: Figs. 1, $6463-4)$. The olfactory tract widens anteriorly, slightly posterior to the prefrontal pillar, forming the 647 reduced olfactory bulbs. It is worth noting that the pair of large obloid concavities on the ventral 648 surfaces of the frontal that traditionally were interpreted as the olfactory bulbs, actually 649 correspond to the olfactory region of the nasal cavity (see Herrera, Fernández \& Gasparini, 650 2013).

In MLP 72-IV-7-1 the cerebral hemispheres are laterally projected and they are

652

653

654

655

656

657

658

659

660

661

662

663

664 noticeably wider (approximately 30\%) than the medulla oblongata (Fig. 7C). The same condition was previously observed in the natural endocasts of the same taxon (e.g. MOZ-PV 7201, MOZPV 7208, MOZ-PV 7261; Herrera, 2015: Fig. 2.2, 2.4), and also noticed in P. typus (Pierce, Williams \& Benson, 2017: Fig 5A), unlike S. bollensis (Fig. 3C) and S. cf. gracilirostris (Brusatte et al., 2016: Fig. 6A-6B).

The anteroposterior elongated pituitary body is located ventral to the midbrain (Fig. 7B, 7F). In lateral view, the pituitary fossa extends from the posterior half of the cerebral hemispheres to pass the posterior margin of the trigeminal foramen (Fig. 7B), as in $S$. cf. gracilirostris (Brusatte et al., 2016: Fig. 6D). The carotid canals enter the pituitary fossa at its posterior end through two separate foramina and two parallel canals exit anteriorly from the pituitary fossa (Fig. 7B, 7F).

The cranioquadrate passage runs from the middle ear cavity to the cranioquadrate foramen and it conveys the stapedial vein into the middle ear cavity (Fig. 7G), as in "M." cf. 
665 westermanni (Fernández et al., 2011) and extant crocodylians (Porter, Sedlmayr \& Witmer, 666 2016).

667 Vascular elements. The rostral and caudal middle cerebral veins, the internal carotid artery, and 668 the orbital artery were reconstructed (Fig. 7). The blood vessel fillings distributed throughout the 669 dorsal region of the cerebral hemispheres and associated to the rostral middle cerebral vein 670 identified on the natural casts of C. araucanensis and D. cf. andiniensis (Herrera, 2015; Herrera 671 \& Vennari, 2015) could not be traced in the digital casts based on CT data of MLP 72-IV-7-1. 672 In lateral view, the rostral middle cerebral vein exits the braincase through the dorsal 673 lobule of the trigeminal foramen, forming a subtle swealling in the endocast of MLP 72-IV-7-1 674 (Fig. 7B). This can be probably related to a low CT resolution, as it is markedly different from 675 the condition of some natural endocasts of C. araucanensis where this vein is clearly identifiable 676 (MOZ-PV 7201, MOZ-PV 7261, MLP 73-II-27-3; Herrera, 2015: Fig. 2). In dorsal view, and in 677 the hindbrain region, approximately at the level of the endosseous labyrinth, the two branches of 678 the caudal middle cerebral vein exit from the dorsal region of the endocast (Fig. 7B, 7D). These 679 branches are dorsolaterally directed and run dorsally and parallel to the middle ear cavity (Fig. 680 7A, 7C). The temporo-orbital/stapedial vein passes ventral to the temporo-orbital foramen 681 suggesting that this vein diverges from the main branch and exits through the temporo-orbital 682 foramen. The same feature is also present in "M." cf. westermanni (MDA 2), S. cf. gracilirostris 683 and Pelagosaurus typus (Brusatte et al., 2016). The temporo-orbital/stapedial vein reaches the 684 middle ear region through the cranioquadrate passage and exits trought the cranioquadrate 685 foramen (Fig. 7H), as it was described for "M." cf. westermanni (Fernández et al., 2011) and $P$. 686 typus (Pierce, Williams \& Benson, 2017). Anterior to the root of the caudal middle cerebral 
687 veins, the dorsal longitudinal sinus in MLP 72-IV-7-1 is continuous anteriorly as a ridge that 688 overlays the dorsal region of the hind-, mid- and forebrain (Fig. 7D).

689 In MLP 72-IV-7-1 the carotid canals were completely reconstructed as these are fully 690 ossified, isolating the internal carotid arteries from the pharyngotympanic sinus (Fig. 7F). This 691 pattern has not been described in any other crocodylomorph. More CT data of metriorhynchids 692 are necessary to confirm if this trait is widespread among Metriorhynchidae or whether it 693 represents an autapomorphy of C. araucanensis. In BSPG 1984 I258, S. cf. gracilirostris 694 (Brusatte et al., 2016), and P. typus (Pierce, Williams \& Benson, 2017) the medial portion of the 695 carotid canals passing through the pharyngotympanic sinus cannot be reconstructed. This could 696 be because in these thalattosuchians, as in extant crocodilians, these portions of the carotid canal 697 remain cartilaginous (Sedlmayr, 2002). In MLP 72-IV-7-1 the longest portion of the carotid 698 canals runs parallel to the midline of the cranium, from the occipital opening to the level of the cochlear duct. In this region, the carotid canals turn abruptly medially towards the midline of the cranium. The carotid canals then become parallel to the main axis of the skull again before

701

702 entering at the posterior end of the pituitary fossa through two separate foramina (Fig. 7F). The diameter of the canals at the level of the pituitary fossa is about $5 \mathrm{~mm}$, slightly thinner than the diameter of the internal carotid foramen $(c a .6 \mathrm{~mm})$.

Clearly separated paired canals exit anteriorly from the pituitary fossa, ventral to the optic nerve (CN II) (Fig. 7B, 7F). The same feature was previously identified in non-metriorhynchid thalattosuchians such as: S. cf. gracilirostris (Brusatte et al., 2016), and Pelagosaurus typus (Pierce, Williams \& Benson, 2017). In MLP 72-IV-7-1 these canals are short (likely because of preservation), with a diameter of approximately $5 \mathrm{~mm}$, comparable to the diameter of the internal carotid canal. In some natural endocasts (MOZ-PV 7203, MOZ-PV 7205 and MOZ-PV 7261) 
710 these paired canals can also be observed in the same region. In recent contributions centered on

711 thalattosuchians, these canals were interpreted as the canals of the orbital artery (Brusatte et al.,

712 2016; Pierce, Williams \& Benson, 2017).

713 Nerves. Only a few cranial nerves were identifiable and reconstructed in MLP 72-IV-7-1. The

714 optic nerve (CN II) originates from the midline, anterodorsal to the pituitary fossa, and exits the

715 braincase through a broad aperture. Cranial nerve IV originates dorsal to the orbital artery (Fig.

$7167 \mathrm{~B}, 7 \mathrm{~F})$. The large trigeminal foramen, located on the lateral wall of the braincase, is a prominent

717 structure that allowed reconstruction of the trigeminal ganglion $(\mathrm{Vg})$, which originates on the

718 lateral surface of the midbrain region (Fig. 7).

719 Paratympanic sinus system. The paratympanic sinus system of C. araucanensis resembles that

720 of S. bollensis. One of the major differences is the absence of the lateral pharyngeal foramina, a

721 feature shared with most metriorhynchids (e.g. Purranisaurus potens, Metriorhynchus

722 superciliosus). As in most crocodylomorphs (e.g. S. bollensis, Protosuchus richardsoni,

723 Simosuchus shushanensis, Notosuchus terrestris, Caiman latirostris), the median pharyngeal

724 foramen is located along the sagittal plane at the suture between the basioccipital and the

725 basisphenoid (Fig. 5B).

726

The pharyngotympanic sinus system is not expanded posteriorly, thus does not form a

727 basioccipital diverticulum. The absence of this feature is unique among crocodyliforms, even

728 when compared with other thalattosuchians (e.g. S. bollensis, see above; S. cf. gracilirostris,

729 Brusatte et al., 2016; Pelagosaurus typus, Pierce, Williams \& Benson, 2017). The median

730 pharyngeal foramen continues anteriorly as a narrow tube, which expands slightly at midlength,

731 pneumatizing the posteroventral region of the basisphenoid (Fig. 7E). From the anterolateral

732 regions of the basisphenoid diverticulum two posterodorsally directed rami, which connect with 
733 the main pharyngotympanic sinus, are present. These ramifications are identified as the anterior

734 communicating canals (sensu Miall, 1878; or recesus epitubaricus sensu Dufeau \& Witmer,

735 2015) and, unlike the morphology present in non-metriorhynchid thalattosuchians, these have

736 little dorsoventral development and are very wide (Fig. 7E). The ventral pneumatization of the

737 floor of the palate is reduced in C. araucanensis as it does not invade the pterygoids.

738 The structure of the main pharyngotympanic sinus of $C$. araucanensis is very similar to

739 that of S. bollensis: the middle ear cavity forms a mediolaterally directed tube limited anteriorly

740 by the quadrates and posteriorly by the otoccipitals; accessory pneumatizations from this cavity

741 are very poorly developed (lacking quadrate and infundibular diverticula); and the prootic

742 diverticulum is represented by an anterodorsal swelling on the cavity (Fig. 7A, 7C). The later, as

743 in other thalattosuchians reported to the date (see above), lacks an isolated diverticulum just

744 anterior to the anterior the semicircular canals. The main difference identified among $C$.

745 araucanensis and $S$. bollensis is on the relative development of the otoccipital diverticulum, as in

746 the former this diverticulum does not form a laminar ventral expansion (Fig. 7G) as it is

747 observed in S. bollensis (Fig. 3G). These laminar ventral expansions of the middle ear cavities

748 (i.e. otoccipital diverticula) are only visible towards the midline, in the posteromedial region of

749 the pharyngotympanic sinus. Another notable difference between the taxa studied in this

750 contribution is the dorsal projection of the otoccipital diverticulum. In C. araucanensis this

751 diverticulum is restricted ventral to the foramen magnum. Cricosaurus araucanensis lacks any

752 dorsal enlargement or connected cavity (i.e. intertympanic diverticulum) on the posterodorsal

753 region of the paratympanic system, similar to other thalattosuchians (Brusatte et al., 2016;

754 Pierce, Williams \& Benson, 2017).

755 Endosseous labyrinth of the inner ear. The anterior, posterior, and lateral semicircular canals, 
756 crus communis, and cochlear duct were reconstructed (Fig. 8). The general morphology of the

757 inner ear is similar to that described in other crocodyliforms. The semicircular canals are aligned

758 in approximately orthogonal planes in three-dimensional space. In MLP 72-IV-7-1, the complete

759 inner ear is approximately $19.5 \mathrm{~mm}$ tall and has a maximum width of $18 \mathrm{~mm}$ at the level of the

760 semicircular canals (Fig. 8). The cochlear ducts do not extend ventrally in comparison with $S$.

761 bollensis. In MLP 72-IV-7-1 the ventralmost point of the duct is level with the ventral region of

762 the brain (Fig. 7G).

763 Discussion

764 Comparative braincase and endocranial anatomy

765 In the sections above we described the braincase and the 3D models of the endocast and

766 other associated structures of two well-preserved thalattosuchians: Steneosaurus bollensis and

767 Cricosaurus araucanensis. Despite recent phylogenetic studies not using the same taxon

768 sampling (e.g. Pol \& Gasparini, 2009; Young et al., 2017), there is a general consensus that the

769 specimens analyzed in this contribution represent members from the two main lineages among

770 thalattosuchians: Teleosauridae and Metriorhynchoidea (see Figs. 9-10). This, along with recent

771 contributions centered on the braincase and other associated structures of thalattosuchians

772 (Fernández et al., 2011; Brusatte et al., 2016; Pierce, Williams \& Benson, 2017), provided the

773 framework to analyze the main changes in this region in Thalattosuchia. In the following lines

774 we will tackle this issue and try to evaluate the different structures individually.

775 Internal carotid foramen and canal. An enlarged foramen for the internal carotid artery was

776 previously proposed as a synapomorphy of Metriorhynchidae (Pol \& Gasparini, 2009). However,

777 as mentioned above, this feature is also present in non-metriorhynchid thalattosuchians such as

778 Teleosaurus cadomensis, S. cf. gracilirostris and Pelagosaurus typus (Jouve, 2009; Brusatte et 
779 al., 2016; Pierce, Williams \& Benson, 2017), and S. pictaviensis (LPP.M.37) and ?Steneosaurus

$780 \mathrm{sp}$. (SMNS 59558) indicating that an enlarged foramen for the internal carotid is a feature widely

781 distributed in Thalattosuchia. An exception are the teleosaurids Machimosaurus buffetauti

782 (SMNS 91415; Martin \& Vincent, 2013) and Peipehsuchus teleorhinus (IVPP V 10098) where

783 this foramen has the same diameter (or is even smaller) than the one for the exit of the

784 hypoglossal cranial nerve (CN XII).

785 In metriorhynchids, an enlarged foramen for the internal carotid artery was linked with an

786 enlargement of the carotid canal (Fernández et al., 2011). An increased artery diameter implies

787 that there is less blood contacting the vessel wall, thus lowering the friction and the resistance,

788 subsequently increasing the flow. Herrera, Fernández \& Gasparini (2013) suggested, based on

789 the known case of extant birds (Gerstberger, 1991), that in metriorhynchids a high amount of the

790 blood flow through the carotid arteries can be diverted to the glands at maximal salt gland

791 secretion. In this sense, the enlargement of the carotid foramen and canal indicates an increase in

792 blood flow that could be coupled with an increase in blood flow to salt glands at maximal

793 secretion. Recently, Brusatte et al. (2016) have used the presence of an enlarged foramen for the

794 internal carotid artery (and also a conspicuous canal) to suggest that large salt glands were also

795 present in the non-metriorhynchid thalattosuchian S. cf. gracilirostris. More recently, Wilberg

796 (2015a) in Zoneait nargorum and, Pierce, Williams \& Benson (2017) in P. typus, described an

797 expansion of the nasal cavity anterior to the orbits and referred this expansion as the osteological

798 correlate of an enlarged salt gland. Again, this claim is coupled with the presence of an enlarged

799 foramen/canal for the internal carotid artery in P. typus (Pierce, Williams \& Benson, 2017).

800 Considering the proposed links mentioned above between the diameter of the carotid foramen

801 and the size of the salt gland, taxa like Machimosaurus buffetauti and Peipehsuchus teleorhinus 
802 would not have enlarged salt glands, if present. Additional to the absence of an enlarged carotid

803 foramen, some specimens of these taxa have been also reported from brackish or continental

804 deposits (Martin \& Vincent, 2013; Martin et al., 2016).

805 Fernández \& Gasparini (2008), following the four stage evolutionary model of

806 osmoregulation strategies of Dunson \& Mazzotti (1989), suggested that marine adaptation in

807 thalattosuchians was transitional, that teleosaurids represent the third state, and metriorhynchids

808 the more extreme fourth stage. That is, teleosaurids lived probably in brackish environments and,

809 occasionally in open sea. As the extant Crocodylus porosus, teleosaurids likely prevented lethal

810 dehydration by means of small salt-secreting glands of low secretory capacity used in

811 conjunction with selective drinking of only hypo-osmotic fresh water. If so, no conspicuous

812 osteological correlates of salt glands must be expected in teleosaurids. On the contrary, the

813 pelagic life-style of metriorhynchids required well-developed salt-secreting glands, such as those

814 preserved as natural casts in Cricosaurus araucanensis (Fernández \& Gasparini, 2008).

815 If enlarged carotid arteries can be used as correlates of an increased blood flow coupled

816 with the blood demand of enlarged salt glands (as proposed by Brusatte et al., 2016) then most

817 thalattosuchians would have had enlarged salt glands with a high secretory capacity, and salt

818 glands of low secreting capabilities were restricted to some teleosaurids such as M. buffetauti and

819 P. teleorhinus. It is worth mentioning that osteological correlates, even in the case of enlarged

820 glands, are not easy to identify. In the case of Cricosaurus araucanensis the identification of

821 these structures was possible as they were preserved as natural casts (see e.g. Fernández \&

822 Gasparini, 2008). It must be noted that the hypothesis about the presence of enlarged salt glands

823 outside Metriorhynchidae is based solely on the indirect evidence of enlarged carotid foramina,

824 and such correlation needs to be validated with fossil specimens displaying enlarged salt glands. 

thalattosuchians these foramina are situated ventral to the occipital condyle, and lateral to the basioccipital tuberosities, while in most crocodylomorphs these foramina are situated at the level 828 of the occipital condyle (e.g. Junggarsuchus sloani, Clark et al., 2004: Fig. 2; Mourasuchus nativus, Bona, Degrange \& Fernández, 2013: Fig. 3B; Caipirasuchus, Pol et al., 2014: Fig. 20B; Notosuchus terrestris, Barrios et al., 2018: Fig. 22F). Among thalattosuchians there is a modification regarding the general orientation of the carotid canal, which affects in which view

832 the foramina are visible on the skull. In metriorhynchoids, they pierce the otoccipital in a 833 posterior direction, and as a result they are only visible in occipital view (e.g. Pelagosaurus typus, Zoneait nargorum, Purranisaurus potens, Plesiosuchus manselii, Maledictosuchus

835 riclaensis, Cricosaurus araucanensis, Fig. 5C). This condition is the most widespread among 836 crocodylomorphs, as in most of them (e.g. Junggarsuchus sloani, Mourasuchus nativus,

\section{Notosuchus terrestris, Protosuchus richardsoni, Gryposuchus neogaeus, Rhabdognathus}

838 aslerensis, Dyrosaurus phosphaticus, Caiman latirostris), the foramina are visible in occipital

839 view. On the other hand, in the teleosaurids Steneosaurus bollensis (Fig. 1D), S. pictaviensis, $S$.

840 leedsi, Machimosaurus buffetauti, P. teleorhinus, and Teleosaurus cadomensis the foramen for

841 the entrance of the carotid artery pierces the otoccipital in a posteroventral, ventrolateral, or even

842 ventral direction. It is worth mentioning that the change in orientation of the internal carotid

843 foramen is only present in the teleosaurids mentioned above, while most of the others exhibit the

844 generalized crocodylomorph condition (e.g. Steneosaurus cf. gracilirostris, Lemmysuchus

845 obtusidens, Steneosaurus edwarsi). However, it should be considered that in some specimens

846 this feature may be exaggerated by post-mortem deformation because a dorsoventral 
847 compression of the skull may cause the internal carotid foramen to be artificially shifted to a

848 more ventral position.

849 Trigeminal foramen. Two different morphologies for the trigeminal foramen have been

850 reported in thalattosuchians: circular (e.g. S. bollensis, M. buffetauti, and likely in T. cadomensis)

851 (e.g. Fig. 1C) and bilobate, constricted or hour-glass shaped (e.g. P. typus, M. brachyrhynchus,

852 "M." cf. westermanni, C. araucanensis and D. cf. andiniensis) (e.g. Fig. 6B-C). A bilobate

853 trigeminal foramen can be recognized in other non-thalattosuchian crocodylomorphs, for

854 example Sphenosuchus (Walker, 1990), Dibothrosuchus elaphros (Wu \& Chatterjee, 1993: Fig.

855 3A), and Notosuchus terrestris (Barrios et al., 2018). However, most crocodyliforms have a

856 circular trigeminal foramen (e.g. Goniopholis stovali, AMNH 5782; Caiman latirostris, MACN

857 30531; Protosuchus haughtoni, Busbey \& Gow,1984; Rhabdognathus aslerensis, Brochu et al.,

858 2002; Simosuchus clarki, Kley et al., 2010; Almadasuchus figarii, Pol et al., 2013).

859 In sum, a bilobate trigeminal foramen appears to be restricted to metriorhynchoids within

860 Thalattosuchia, whereas teleosaurids retain the plesiomorphic condition of a circular trigeminal

861 foramen (Figs. 9-10). Although preliminary, as this feature needs to be tested thoroughly in a

862 phylogenetic context, occurrences of bilobate trigeminal foramina seem to be isolated outside

863 Metriorhynchoidea, contrasting with the widespread condition of a circular one. This particular

864 morphology has been associated to the separation of the maxillary $\left(\mathrm{CN} \mathrm{V}_{2}\right)$ and mandibular $(\mathrm{CN}$

$865 \mathrm{~V}_{3}$ ) branches of the CN V (Barrios et al., 2018).

866 Cranial nerves IX-XI and XII. The presence of a metotic foramen with a unique or double

867 opening has been recognized within Thalattosuchia. We interpreted that Steneosaurus bollensis

868 (Fig. 1D), Pelagosaurus typus, Purranisaurus potens, and Dakosaurus cf. andiniensis have a

869 single opening. In the holotype of "Metriorhynchus" casamiquelai (MGHF 1-08573) there is also 
870 one opening for these cranial nerves, while Soto-Acuña, Otero \& Rubilar-Rogers (2012: Fig. 2)

871 identified two foramina for the exit of the CN IX-XI in other specimen referred to

872 "Metriorhynchus" casamiquelai. In contrast, in C. araucanensis (Fig. 5C), the metriorhynchid

873 specimen from Mörnsheim Formation (BSPG 1973 I195), "M." westermanni, "M." cf.

874 westermanni, M. brachyrhynchus (LPP.M 22), and Teleosaurus cadomensis there is a double

875 opening for the exit of cranial nerves IX, X and XI.

876 Related to the exit for CN XII, most thalattosuchians have only one foramen, except for

877 Pelagosaurus typus, M. brachyrhynchus (LPP.M 22), and likely "M." casamiquelai. The

878 presence of a single foramen is shared with other crocodylomorphs (e.g. Gryposuchus neogaeus,

879 some Rhabdognathus species). Although it is a different condition in comparison with most

880 crocodylomorphs (e.g. Protosuchus, Sphenosuchus, Almadasuchus, Notosuchus terrestris,

881 Dibothrosuchus elaphros) that have two foramina.

882 It must be considered the possibility that in some cases where more than one foramina is 883 interpreted as the exit for CN IX-XI, the medialmost could corresponds to a second opening for

884 CN XII. This uncertainty can be resolved with complete reconstructions of the passage of the 885 nerves, based on CT data, but unfortunately in the specimens that we are describing this is not 886 possible because the resolution of CT data does not allow tracing of these passages. Within the 887 studied thalattosuchians, there is variability in the number, relative size, or location of the cranial 888 nerve foramina on the posterior aspect of the skull (see also Brusatte et al., 2016).

889 Separation of the cranioquadrate canal from the external otic aperture. The cranioquadrate 890 canal is a structure present in hallopodid crocodylomorphs, mesoeucrocodylians and derived 891 crocodyliforms (i.e. Fruitachampsa, Gobiosuchus, Hsiosuchus) (Clark, 1994; Leardi, Pol \&

892 Clark, 2017). The cranioquadrate canal connects the middle ear space with the posterior aspect of 
893 the skull, which additionally serves to transmit the stapedial artery and vein (Iordansky, 1973;

894 Porter, Sedlmayr \& Witmer, 2016). In thalattosuchians the cranioquadrate foramen is placed

895 more laterally than in most crocodyliforms, a condition reported as synapomorphy for the group

896 (Clark, 1994).

897 In this contribution we report a further derived condition for the cranioquadrate passage

898 present in all metriorhynchids and some telesaurids, in which the cranioquadrate foramen is

899 completely separated from the external otic aperture by a thin bony lamina. This condition is

900 present in the metriorhynchids Cricosaurus araucanensis (Fig. 5C), Maledictosuchus riclaensis,

901 Torvoneustes coryphaeus, Purranisaurus potens, "Metriorhynchus" casamiquelai, and in the

902 teleosaurids Machimosaurus buffetauti and ?Steneosaurus sp. (SMNS 59558). Aditionally, Jouve

903 (2009) mentioned that these structures are also completely separated in Mystriosaurus cf.

904 bollensis, Teleidosaurus, and Enaliosuchus. In contrast, based on first hand examinations of the

905 specimens, we found that the cranioquadrate canal is incompletely separated from the external

906 otic recess in Pelagosaurus typus (BSPG 1890 I5, NHMUK PV R.32599) and Steneosaurus

907 pictaviensis (LPP.M.37). According to Jouve (2009) the same feature ocurrs in Teleosaurus

908 cadomensis, Steneosaurus larteti, Pelagosaurus typus, and Steneosaurus bollensis. The

909 distribution of this character within non-metriorhynchid thalattosuchians appears to be a highly

910 homoplastic trait. However it should be considered that the complete separation of the

911 cranioquadrate canal and the external otic recess in some non-metriorhynchid thalattosuchians

912 could be cartilaginous. This is based on our observations of the specimen Pelagosaurus typus

913 (BSPG 1890 I5) where the separation of both structures is incomplete, but the bony laminae

914 almost contact each other. Yet, the separation is very difficult to evaluate in internal structures in 
915 fossil taxa, as the osteological marks left by the cartilage can be very subtle (e.g. Holliday \&

916 Witmer, 2008).

917 Absence of flexures. Most extant and extinct crocodylomorphs have, at least, a well-marked

918 mid-hindbrain flexure, giving the encephalon a curved profile in lateral view (e.g. Pholidosaurus

919 meyeri, MB.R.2027; Macelognathus, Leardi, Pol \& Clark, 2017; Sebecus icaeorhinus, Colbert,

920 1946a: pl. 14A; Crocodylus johnstoni, Witmer et al., 2008: Fig. 6.3; Simosuchus clarki, Kley et

921 al., 2010: Fig. 32C; Gavialis gangeticus, Bona, Paulina Carabajal \& Gasparini, 2017: Fig. 7). In

922 this sense, the presence of a straight brain (i.e. absence of flexures between fore-midbrain, and

923 mid-hindbrain), appears to be characteristic for Thalattosuchia (e.g. Herrera, 2015; Herrera \&

924 Vennari, 2015; Brusatte et al., 2016; Pierce, Williams \& Benson, 2017).

925 The tubular brain of thalattosuchians can be coupled with two morphological traits

926 present in their skulls. Most thalattosuchians have a very long and tubular snout which does not

927 have an abrupt transition between its dorsal edge and the anterior end of the skull roof (i.e. the

928 anterior end of the frontal). This feature is particularly marked in C. araucanensis (Gasparini \&

929 Dellapé, 1976: Lam, 1-2), where the anterodorsal part of the snout is almost straight with the

930 skull roof. This particular transition between the skull roof and the snout has been previously

931 noted in other non-thalattosuchian crocodylomorphs like Sebecus icaeorhinus and baurusuchids

932 (Colbert, 1946a; Carvalho, Campos \& Nobre, 2005). Also, Sebecus has a fore-midbrain flexure

933 with an angle comparable to the one observed in thalattosuchians (see Pierce, Williams \&

934 Benson, 2017). On the other hand, the mid-hindbrain flexure could be hidden by the

935 development of the large dorsal venous sinus on the posterodorsal region of the encephalon, that

936 overlies this region and obscures the real nature of the flexure. However, these interpretations

937 need to be thoroughly tested as other taxa like Simosuchus have acute angles between parts of its 
938 encephalon attaining values similar to the ones present in thalattosuchians (Pierce, Williams \&

939 Benson, 2017). It is important to note that, to the present day, CT data and 3D endocast models

940 for crocodylomorphs are very few and more data could easily change the interpretations

941 presented in here.

942 Cephalic vascularization. The cephalic vascular system in Thalattosuchia is characterized by a

943 well-developed caudal middle cerebral vein/stapedial vein/temporo-orbital vein, internal carotid

944 artery, and orbital artery (see also Fernández et al., 2011; Herrera, Fernández \& Gasparini, 2013;

945 Herrera, 2015; Herrera \& Vennari, 2015; Herrera, 2016a; Brusatte et al., 2016; Pierce, Williams

946 \& Benson, 2017). Additionally, descriptions of natural brain endocasts of metriorhynchids

947 (Herrera, 2015; Herrera \& Vennari, 2015) showed that several blood vessels cover the dorsal

948 region of the cerebral hemispheres, and are associated with the rostral middle cerebral vein. This

949 enlarged vascular system indicates an important blood supply to the head of thalattosuchians.

950 A plausible functional explanation about the enlarged cephalic vascular system in

951 Thalattosuchia is that it can play a role in cephalic physiological thermoregulation. The orbital

952 artery supplies the posterior aspect of the orbit, whereas the venous drainage of the orbit is

953 mainly via the temporo-orbital veins. Extant crocodilians have the orbital region well

954 vascularized and arteries and veins form a plexus within the orbit, potentially allowing heat

955 exchange (Porter, Sedlmayr \& Witmer, 2016). In C. araucanensis and S. cf. gracilirostris, the

956 orbital artery is approximately the same diameter as the internal carotid artery. In both taxa and

957 also in "Metriorhynchus" cf. westermanni, Dakosaurus cf. andiniensis, and Pelagosaurus typus

958 the temporo-orbital vein is also well developed. This suggests that these blood vessels were

959 capable of transmitting a large volume of blood to the orbit. Blood shunts or countercurrent heat

960 exchangers have been described for several species of reptiles as responsible for regional 
961 temperature differences (Heath, 1966; Crawford, Palomeque \& Barber, 1977). The blood vessels

962 infillings that cover the cerebral hemispheres and derive from the rostral middle cerebral vein

963 described in metriorhynchids (Herrera, 2015; Herrera and Vennari, 2015) could be acted as heat

964 exchangers. As mentioned by Porter, Sedlmayr \& Witmer (2016), the anatomical and

965 physiological roles that blood vessels play in extant crocodylian thermoregulation need further

966 investigation. Other funtional alternative is that the enlarged cephalic vascular system could be

967 related with a mitigation of the impact of hydrostatic pressures on organs and neural tissues.

968 However the exploration of this alternative require further exploration and it is beyond the scope

969 of the present contribution.

970 Lateral pharyngeal foramen (pharyngotympanic tube). The pharyngotympanic tubes connect

971 the middle ear cavity with the pharynx and are part of the mechanism used in several amniotes to

972 equalize pressures of the middle ear and the external environment (Dufeau \& Witmer, 2015).

973 In metriorhynchids the lateral pharyngeal foramina are closed as the basisphenoid

974 contacts the otoccipital and the basioccipital along its posterolateral edge (Fig. 5B). On the other

975 hand, teleosaurids (e.g. S. bollensis, BSPG 1984 I258, Fig. 1B; S. pictaviensis, LPP.M.37;

976 Lemmysuchus obtusidens, LPP.M.21; Teleosaurus cadomensis, Jouve, 2009) and the basal

977 metriorhynchoid Pelagosaurus typus (BSPG 1890 I5) bear lateral Eustachian foramina, as most

978 crocodyliforms (e.g. Protosuchus haughtoni, Notosuchus terrestris, Rhabdognathus aslerensis,

979 Caiman latirostris).

980 Within Thalattosuchia the closure of the lateral pharyngeal foramina appears to be

981 restricted to metriorhynchids, while non-metriorhynchid thalattosuchians retain the

982 plesiomorphic condition of bearing lateral pharyngeal foramina. Besides the closure of the lateral

983 pharyngeal foramina, additional variation can be reported in thalattosuchians. In teleosaurid taxa, 
984 restricted to the genus Steneosaurus (e.g. S. bollensis, BSPG 1984 I258; S. pictaviensis,

985 LPP.M.37), the median pharyngeal foramen is smaller than lateral ones, while Peipehsuchus

986 teleorhinus (IVPP V 10098) retains the typical crocodyliform condition where the medial

987 foramen is the largest of the pharyngeal foramina.

988 The absence of the lateral pharyngeal foramina in metriorhynchids implies that the

989 communication between the middle ear cavity with the pharynx is reduced to the median

990 pharyngeal foramen. Further studies are needed to understand if this modification has a

991 physiological/adaptive significance.

992 Reduction of the paratympanic sinus system. According to Dufeau (2011) and Dufeau \&

993 Witmer (2015) in most mesoeucrocodylian crocodyliforms (Sebecus icaeorhinus;

994 Hamadasuchus rebouli; and extant crocodiles like Alligator mississippiensis), diverticular

995 expansions are extensive whereas in longirostrine taxa such as Gavialis, Tomistoma,

996 Rhabdognathus aslerensis and Pelagosaurus there is a constraint on diverticular pneumatization

997 of the anterior portion of the braincase.

998 The constraint on diverticular pneumatization is more evident in Thalattosuchia, in 999 comparison to extant and extinct crocodiles, given by the absence of the infundibular, quadrate,

1000 intertympanic diverticula, likely the prootic diverticulum and also a restricted pneumatization of 1001 the otoccipital (see also Brusatte et al., 2016; Pierce, Williams \& Benson, 2017). This reduction 1002 is more developed in Cricosaurus araucanensis than in Steneosaurus bollensis. The former also 1003 lacks a basioccipital diverticulum and the otoccipital diverticulum has no dorsal projection (in 1004 comparison to $S$. bollensis). Future work should confirm if this condition is restricted to $C$. 1005 araucanensis or if it is more widely distributed among metriorhynchids. 

documented in non-crocodyliform crocodylomorphs, although pneumatic anterior foramina have been reported in several taxa (e.g. Terrestrisuchus, Dibothrosuchus, Junggarsuchus, Almadasuchus, Macelognathus), and in some of them the connection with the middle ear cavity was confirmed (Leardi, Pol \& Clark, 2017). As it was observed with the peculiar shape of the otic aperture, the lack of a subtympanic foramen (sensu Montefeltro, Andrade \& Larsson, 2016) and an associated infundibular diverticulum is common to most thalattosuchians (e.g. $S$. bollensis, T. cadomensis, P. typus, C. araucanensis). pneumatization in thalattosuchians, a feature widely distributed among derived crocodylomorphs (see above), has gone unnoticed in recent analysis of the paratympanic pneumaticity of thalattosuchians (Wilberg, 2015b; Brusatte et al., 2016; Pierce, Williams \& Benson, 2017). The lack of dorsal communication via an intertympanic sinus could be representing a generalized loss of paratympanic pneumaticity in thalattosuchians, an idea supported by the condition seen in other regions of the braincase (e.g. otoccipital). Thus, more information is needed to understand the thalattosuchian changes in pneumaticity to support the claim that the absence of the intertympanic sinus is due to a non-crocodyliform position within the crocodylomorph phylogeny or if it represents a regression. non-crocodyliform crocodylomorphs and crocodyliforms (Pol et al., 2013; Leardi, Pol \& Clark, 1028 2017), where the otoccipital diverticulum is dorsally extended, exceeding the dorsal border of the 
1029 foramen magnum. This contrasts with the thalattosuchian condition, in which the diverticulum is 1030 mostly restricted to the ventral part of the otoccipital.

1031 Pneumatic diverticula associated with the middle ear cavity of crocodylomorphs have 1032 been described and analyzed several times (e.g. Colbert, 1946b; Tarsitano, 1985; Dufeau \& 1033 Witmer, 2015). However, the functional interpretations related to this particular crocodylomorph 1034 specialization remain elusive. Given that interaural time differences have been reported for 1035 crocodylians (Carr et al., 2009), Bierman et al. (2014) hypothesized that the pneumatic diverticula coupled both ears internally, allowing the crocodylian ear to act as a pressure difference receiver organ and, thus, permiting directional hearing. A second hypothesis was proposed by Dufeau \& Witmer (2015), in which the development of the paratympanic pneumatic diverticula increases the auditory sensitivity. In particular, Dufeau \& Witmer (2015) found that the resonant frequencies calculated on the subtympanic foramen coincided with the greatest intensity of juvenile vocalizations of Alligator mississippiensis, while these distress calls where among the lowest threshold of cochlear sensitivity in adults. Thus, it was associated to have a function in increasing the auditory sensitivity from adults towards their offspring. Due to the recent increasing amount of available CT data of thalattosuchians we can conclude that the group as a whole lacks the intertympanic diverticulum, and has a reduced dorsal pneumatization associated with the otic capsule (see above). However, internal connections between both middle ears are still retained through the ventral part of the pharyngotympanic and median pharyngeal systems, thus allowing internal ear coupling and the associated sound localization. As a result, we can infer a reduced response in directional hearing in thalattosuchians and a decrease in low frequency sensitivity (Bierman et al., 2014), due to the loss of the dorsal paratympanic 
1052 foramen can be discarded for thalattosuchians. As it was discussed in this contribution,

1053 thalattosuchians lack pneumatic foramina and associated pneumatization in the quadrate.

1054 Braincase and endocranial anatomy evolution of thalattosuchians

1055 In order to trace morphological transformations and major changes in the braincase and

1056 endocranial anatomy along crocodylomorph evolution, the distribution of the anatomical features

1057 that we discussed above were mapped in two phylogenetic hypotheses for the clade:

1058 Thalattosuchia as derived neosuchians, nested with pholidosaurs/dyrosaurids forming a

1059 "longirostrine clade" (Fig. 9; Clark, 1994; Pol \& Gasparini, 2009; Leardi, Pol \& Clark, 2017); or

1060 Thalattosuchia as the sister group to Crocodyliformes (Fig. 10; Wilberg, 2015b; Young et al.,

1061 2017). This approach is due to the unresolved phylogenetic affinities of Thalattosuchia.

1062 Under both phylogenetic hypotheses the enlarged foramen for the internal carotid, the

1063 carotid foramen ventral to the occipital condyle, an orbital process of the quadrate free of bony

1064 attachment, a laterosphenoid-prootic suture forming a pronounced ridge, the absence of a a

1065 subtympanic foramen, the absence of brain flexures, the hypertrophied cephalic vascular system

1066 (i.e. the enlargement of the carotids and orbital arteries as well as temporo-orbital veins), and the

1067 reduction of the paratympanic sinus system are putative synapomorphic features of

1068 Thalattosuchia (Figs. 9-10). Thalattosuchians are very diverse and some of these features exhibit

1069 reversions, showing instances of homoplasies (e.g. double foramen for the exit of CN XII in

1070 some thalattosuchians and the absence of an enlarged carotid foramen in Machimosaurus and

1071 Peipehsuchus). However, some of the traits discussed are unknown in many crocodylomorphs,

1072 either due to the lack of well-preserved braincases, incomplete descriptions in the literature of

1073 this area, or the lack of internal anatomical data (e.g. CT data). 
Although a general pattern of braincase configuration is evident in Thalattosuchia, other

1075

1076

1077

1078

1079

1080

1081

1082

1083

1084

1085

1086

1087

1088

1089

1090

1091

1092

1093

1094

1095

1096

morphological traits characterize less inclusive clades. Such is the case with the shape of the

trigeminal foramen. In the topology of Pol et al. (2014) (Fig. 9) the bilobate trigeminal foramen characterizes Metriorhynchidae, although a bilobate trigeminal foramen is also present in the non-metriorhynchid thalattosuchian Pelagosaurus typus. On the other hand, based on the topology of Young et al. (2017) the bilobate trigeminal foramen is a putative synapomorphy of Metriorhynchoidea. In both phylogenetic hypotheses the loss of the lateral Eustachian foramina is a putative synapomorphy of Metriorhynchidae (Figs. 9-10). This feature could be coupled with the general reduction evidenced in the paratympanic sinus system (absence of basioccipital and pterygoid diverticula) of Cricosaurus araucanensi s. However, in order to evaluate if this condition is extended among other members of Metriorhynchidae, futher descriptions of the metriorhynchid paratympanic sinus system are required.

\section{Conclusions}

The braincase and endocranial morphology of the teleosaurid Steneosaurus bollensis and the metriorhynchid Cricosaurus araucanensis are described in this contribution. The descriptions of two members of different clades of Thalattosuchia allowed us to evaluate and contrast the main features of the braincase and endocranial anatomy with other crocodylomorphs. The main traits that characterize Thalattosuchia from other crocodylomorphs are: enlarged foramen for the internal carotid artery, the carotid foramen ventral to the occipital condyle, a single CN XII foramen, the absence of brain flexures, the well-developed cephalic vascular system, the absence of a subtympanic foramen, and the reduction of the paratympanic sinus system. Some of these features (enlarged foramen for the internal carotid artery, the absence of brain flexures, the hypertrophied cephalic vascular system), were previously suggested as exclusively present in 
1097 Metriorhynchidae, and associated to the pelagic lifestyle of this lineage; however recent studies

1098 revealed that they were already established at the base of Thalattosuchia.

From the paleobiological perspective, these changes indubitably had consequences for the

1100 biology of these animals. We suggest that the well-developed vascular system was not only

1101 related to the secretory function of salt glands, but also it played a role in the cephalic

1102 physiological thermoregulation. Also, the reduction of the paratympanic pneumatization is

1103 related to a reduced response in directional hearing in thalattosuchians and a decrease in low

1104 frequency sensitivity. However these interpretations should be tested in the light of new

1105

1106

1107

1108

1109

1110

1111

1112

1113

1114

1115

1116

1117

1118

1119

information about extant and extinct archosaurs.

As it was mentioned above, the main modifications on the braincase and endocranial anatomy appear to be present even in the basalmost members of the clade. These findings do not support an adaptive gap between fully pelagic forms (metriorhynchids) and semiaquatic ones (teleosaurids), implying that these features were already present in the lineage and might have been exapted later on their evolutionary history.

We recognized differences within Thalattosuchia that previously have not received much attention or even were overlooked (e.g. circular/bilobate trigeminal foramen, single/double CN XII foramen, separation of the cranioquadrate canal from the external otic aperture, absence/presence of lateral pharyngeal foramen). The new information on the braincase and endocranial morphology of thalattosuchians adds anatomical information that has potential use in taxonomy, phylogeny, and paleobiology.

The functional significance of these traits is still unclear. Extending the sampling to other thalattosuchian taxa will help to test the timing of acquisition and distribution of these morphological modifications among the whole lineage. Also comparison with extant marine 
1120 tetrapods (including physiological information) will be crucial to understand if some (and/or

1121 which) of the morphological peculiarities of thalattosuchian braincases are products of

1122 directional natural selection resulting in full adaptation to a nektonic life style.

\section{Acknowledgements}

1124 We thank C. Mehling and M. Norell (AMNH), O. Rauhut (BSPG), W. Joyce, P. Havrlik and M. 1125 Aiglstorfer (GPIT), F. Zheng and X. Xu (IVPP), P. Vignaud and G. Garcia (LPP), A. Kramarz 1126 (MACN), T. Schossleitner and D. Schwarz (MB.R.), A. Garrido and B. Bollini (MOZ), J.I.

1127 Canudo (MPZ), L. Steel (NHMUK), R. Schoch (SMNS), and P. Holroyd (UCMP) for provided 1128 access to specimens under their care and valuable help during collection visits. We thank G.

1129 Rößner (BSPG) for providing assistance with CT scanning. We would like thank F. Degrange 1130 (CICTERRA) and M. Bronzati (FFCLRP-USP) for their technical support. We are also grateful 1131 to S. Walsh, G. Sobral and E. Wilberg for constructive comments and valuable insights, and 1132 Fabien Knoll for handling the manuscript. YH deeply thanks O. Rauhut (BSPG) for his support 1133 during her stay in Munich.

\section{References}

1135 Andrews CW. 1913. A descriptive catalogue of the marine reptiles of the Oxford Clay, Part Two. London: British Museum (Natural History), 285.

Bardet N, Falconnet J, Fischer V, Houssaye A, Jouve S, Pereda Suberbiola X, Pérez-García A, Rage J-C, Vincent P. 2014. Mesozoic marine reptile palaeobiogeography in response to drifting plates. Gondwana Research 26:869-887. http://dx.doi.org/10.1016/j.gr.2014.05.005 mandibular anatomy of Notosuchus terrestris (Crocodyliformes, Mesoeucrocodylia) from 
1143

1144

1145

1146

1147

1148

1149

1150

1151

1152

1153

1154

1155

1156

1157

1158

1159

1160

1161

1162

1163

1164

the Upper Cretaceous of Patagonia. Cretaceous Research 83:3-39.

http://dx.doi.org/10.1016/j.cretres.2017.08.016

Bierman HS, Thornton JL, Jones HG, Koka K, Young BA, Brandt C, ChistensenDalsgaard J, Carr CE, Tollin DJ. 2014. Biophysics of directional hearing in the American alligator (Alligator mississippiensis). The Journal of Experimental Biology 217:1094-1107.

Bona P, Degrange FJ, Fernández MS. 2013. Skull anatomy of the bizarre crocodilian Mourasuchus nativus (Alligatoridae, Caimaninae). The Anatomical Record 296:227-239. DOI 10.1002/ar.22625.

Bona P, Paulina Carabajal A. 2013. Caiman gasparinae sp. nov., a huge alligatorid (Caimaninae) from the late Miocene of Paraná, Argentina. Alcheringa 37:1-12.

Bona P, Paulina Carabajal A, Gasparini Z. 2017. Neuroanatomy of Gryposuchus neogaeus (Crocodylia, Gavialoidea): a first integral description of the braincase and endocranial morphological variation in extinct and extant gavialoids. Earth and Environmental Science Transactions of the Royal Society of Edinburgh 106:235-246. doi:10.1017/S1755691016000189

Brochu CA, Bouare ML, Sissoko F, Roberts EM, O’Leary MA. 2002. A dyrosaurid crocodyliform braincase from Mali. Journal of Paleontology 76:1060-1071.

Brusatte SL, Muir A, Young MT, Walsh S, Steel L, Witmer LM. 2016. The braincase and neurosensory anatomy of an Early Jurassic marine crocodylomorph: implications for crocodilian sinus evolution and sensory transitions. The Anatomical Record 299:15511530. 
1165 Busbey AB, Gow C. 1984. A new protosuchian crocodile from the Upper Triassic Elliot

1166 Formation of South Africa. Palaeontologia Africana 25:127-149.

1167 Carr CE, Soares D, Smolders J, Simon JZ. 2009. Detection of Interaural Time Differences in 1168 the Alligator. The Journal of Neuroscience 29:7978-7982.

1169 Carvalho IS, Campos ACA, Nobre PH. 2005. Baurusuchus salgadoensis, a new

1170 Crocodylomorpha from the Bauru Basin (Cretaceous), Brazil. Gondwana Research 8:11117130.

1172 Clark JM. 1986. Phylogenetic relationships of the crocodylomorphs archosaurs. D. Phill.

1173 Thesis, University of Chicago.

1174

1175

1176

1177

1178

1179

1180

1181

1182

1183

1184

1185

1186

Clark JM. 1994. Patterns of evolution in Mesozoic Crocodyliformes. In: Fraser NC, Sues H-D, eds. In the shadow of the dinosaurs. Cambridge: Cambridge University Press, 84-97.

Clark JM, Xu X, Forster CA, Wang Y. 2004. A Middle Jurassic "sphenosuchian" from China and the origin of the crocodilian skull. Nature 430:1021-1024. DOI 10.1038 /nature02802.

Colbert EH. 1946a. Sebecus, representative of a peculiar suborder of fossil Crocodylia from Patagonia. Bulletin of the American Museum of Natural History 87:2017-2270.

Colbert EH. 1946b. The eustachian tubes in crocodiles. Copeia 1946:12-14.

Crawford EC, Palomeque J, Barber BJ. 1977. A physiological basis for head-body temperature differences in a panting lizard. Comparative Biochemistry and Physiology Part A: Physiology 56:161-163.

Dufeau DL. 2011. The evolution of cranial pneumaticity in Archosauria: patterns of paratympanic sinus development. D. Phil. Thesis, Ohio University. 
1187 Dufeau DL, Witmer LM. 2015. Ontogeny of the middle-ear air-sinus system in Alligator

1188

1189

1190

1191

1192

1193

1194

1195

1196

1197

1198

1199

1200

1201

1202

1203

1204

1205

1206

1207

1208

mississippiensis (Archosauria: Crocodylia). PLOS ONE 10(9):e013706.DOI

10.1371/journal.pone.0137060.

Dunson WA, Mazzoti FJ. 1989. Salinity as a limiting factor in the distribution of reptiles in Florida bay: a theory for the estuarine origin of marine snakes and turtles. Bulletin of Marine Science 44:229-244.

Fernández MS, Gasparini Z. 2008. Salt glands in the Jurassic metriorhynchid Geosaurus: implications for the evolution of osmoregulation in Mesozoic crocodyliforms. Naturwissenschaften 95:79-84. DOI 10.1007/s00114-007-0296-1.

Fernández MS, Paulina Carabajal A, Gasparini Z, Chong Diaz G. 2011. A metriorhynchid crocodyliform braincase from northern Chile. Journal of Vertebrate Paleontology 31:369-377. DOI 10.1080/02724634.2011.550361.

Foffa D, Young MT. 2014. The cranial osteology of Tyrannoneustes lythrodectikos (Crocodylomorpha: Metriorhynchidae) from the Middle Jurassic of Europe. PeerJ 2:e608DOI 10.7717/peerj.608

Fraas E. 1902. Die Meer-Krocodilier (Thalattosuchia) des oberen Jura unter specieller berucksichtigung von Dacosaurus und Geosaurus. Paleontographica 49:1-72.

Gasparini Z, Dellapé D. 1976. Un nuevo cocodrilo marino (Thalattosuchia, Metriorhynchidae) de la Formación Vaca Muerta (Jurásico, Tithoniano) de la Provincia del Neuquén (Argentina). $\left[1^{\circ}\right.$ Congreso Geológico Chileno (Santiago), Actas]:1-21.

Gerstberger R. 1991. Partial uncoupling of salt gland blood flow and secretion in the pekin duck (Anas platyrhynchos). Journal of Physiology 435:175-186. 
1209 Heath JE. 1966. Venous shunts in the cephalic sinuses of horned lizards. Physiological Zoology

1210

1211

1212

1213

1214

1215

1216

1217

1218

1219

1220

1221

1222

1223

1224

1225

1226

1227

1228

1229

1230

1231 39:30-35.

Herrera Y. 2015. Metriorhynchidae (Crocodylomorpha: Thalattosuchia) from Upper JurassicLower Cretaceous of Neuquén Basin (Argentina), with comments on the natural cats of the brain. In: Fernández MS, Herrera Y, eds. Reptiles Extintos-Volumen en Homenaje a Zulma Gasparini. 15. Publicación Electrónica de la Asociación Paleontológica Argentina, 159-171.

Herrera Y. 2016a. Endocranial anatomy of a marine Crocodylomorpha (Thalattosuchia): a preliminary study. Zitteliana 88:26.

Herrera Y, Vennari VV. 2015. Cranial anatomy and neuroanatomical features of a new specimen of Geosaurini (Crocodylomorpha: Metriorhynchinae) from west-central Argentina. Historical Biology 27:33-41. DOI 10.1080/08912963.2013.861831.

Herrera Y, Fernández MS, Gasparini Z. 2013. The snout of Cricosaurus araucanensis: a case study in novel anatomy of the nasal region of metriorhynchids. Lethaia 46:331-340. DOI 10.1111/let.12011.

\section{Herrera Y, Fernández MS, Lamas GS, Campos L, Talevi M, Gasparini Z. 2017.} Morphology of the sacral region and reproductive strategies of Metriorhynchidae: a counter-inductive approach. Earth and Environmental Science Transactions of the Royal Society of Edinburgh 106:247-255. http://dx.doi.org/10.1017/S1755691016000165

Herrera Y, Gasparini Z, Fernández MS. 2013. A new Patagonian species of Cricosaurus (Crocodyliformes, Thalattosuchia): first evidence of Cricosaurus in Middle-Upper Tithonian lithographic limestone from Gondwana. Palaeontology 56:663-678. DOI $10.1111 /$ pala. 12010 
1232 Herrera Y, Gasparini Z, Fernández MS. 2015. Purranisaurus potens Rusconi, an enigmatic

1233

1234

1235

1236

1237

1238

1239

1240

1241

1242

1243

1244

1245

1246

1247

1248

1249

1250

1251

1252

metriorhynchid from the Late Jurassic-Early Cretaceous of the Neuquén Basin. Journal of Vertebrate Paleontology 35:e904790. DOI: 10.1080/02724634.2014.904790

Holliday CM, Witmer LM. 2008. Cranial kinesis in dinosaurs: intracranial joints, protractor muscles, and their significance for cranial evolution and function in diapsids. Journal of Vertebrate Paleontology 28:1073-1088.

Holliday CM, Witmer LM. 2009. The epipterygoid of crocodyliforms and its significance for the evolution of the orbitotemporal region of eusuchians. Journal of Vertebrate Paleontology 29:715-733.

Hua S, De Buffrenil V. 1996. Bone histology as a clue to the interpretation of functional adaptations in the Thalattosuchia. Journal of Vertebrate Paleontology 16:703-717. DOI 10.1080/02724634.1996.10011359.

Iordansky NN. 1973. The skull of Crocodylia. In: Gans C, Parsons TS, eds. Biology of reptilia. Vol. 4. New York: Academic Press, 201-264.

Jaeger GF. 1828. Über die Fossile Reptilien, welche in Württemberg aufgefunden worden sind. Stuttgart: Metzler, 48.

Johnson MM, Young MT, Steel L, Foffa D, Smith AS, Hua S, Havlik P, Howlett EA, Dyke G. 2017. Re-description of 'Steneosaurus' obtusidens Andrews, 1909, an unusual macrophagous teleosaurid crocodylomorph from the Middle Jurassic of England. Zoological Journal of the Linnean Society 182:385-418. https://doi.org/10.1093/zoolinnean/zlx035 
1253 Jouve S. 2009. The skull of Teleosaurus cadomensis (Crocodylomorpha; Thalattosuchia), and 1254 phylogenetic analysis of Thalattosuchia. Journal of Vertebrate Paleontology 29:88-102.

1255

1256

1257

1258

1259

1260

1261

1262

1263

1264

1265

1266

1267

1268

1269

1270

1271

1272

1273

1274

1275 DOI 10.1080/02724634.2009.10010364.

Kley NJ, Sertich JW, Turner AH, Kause DW, O'Connor PM, Georgi JA. 2010. Craniofacial morphology of Simosuchus clarki (Crocodyliformes: Notosuchia) from the Late Cretaceous of Madagascar. Society of Vertebrate Paleontology Memoir 10:13-98. DOI $10.1080 / 02724634.2010 .532674$.

Leardi JM, Pol D, Clark JM. 2017. Detailed anatomy of the braincase of Macelognathus vagans Marsh, 1884 (Archosauria, Crocodylomorpha) using high resolution tomography and new insights on basal crocodylomorph phylogeny. PeerJ 5:e2801. DOI $10.7717 /$ peerj. 2801

Martin JE, Deesri U, Liard R, Wattanapituksakul A, Suteethorn S, Lauprasert K, Tong H, Buffetaut E, Suteethorn V, Suan G, Telouk P, Balter V. 2016. Strontium isotopes and the long-term residency of thalattosuchians in the freshwater environment. Paleobiology 42:143-156. doi:10.1017/pab.2015.42

Martin JE, Vincent P. 2013. New remains of Machimosaurus hugii von Meyer, 1837 (Crocodylia, Thalattosuchia) from the Kimmeridgian of Germany. Fossil Record 16:179196. DOI 10.1002/mmng.201300009.

Massare JA. 1988. Swimming capabilities of Mesozoic marine reptiles: implications for method of predation. Paleobiology 14:187-205. doi.org/10.1017/S009483730001191

Mazin J-M. 2001. Mesozoic marine reptiles: an overview. In: Mazin J-M, de Buffrénil V, eds. Secondary Adaptation of Tetrapods to Life in Water. München: Verlag Dr. Friedrich Pfeil, 95-117. 
1276 Miall LC. 1878. The Skull of the Crocodile. London: Macmillan and Co, 50.

1277 Montefeltro FC, Andrade DV, Larsson HCE. 2016. The evolution of the meatal chamber in crocodyliforms. Journal of Anatomy 228:838-863. DOI: 10.1111/joa.12439.

1279

1280

1281

1282

1283

1284

1285

1286

1287

1288

1289

1290

1291

1292

1293

1294

1295

1296

1297

1298

Parrilla-Bel J, Young MT, Moreno-Azanza M, Canudo JI. 2013. The first metriorhynchid crocodylomorph from the Middle Jurassic of Spain, with implications for evolution of the subclade Rhacheosaurini. PLoS ONE 8:e54275.DOI 10.1371/journal.pone.0054275.

Pierce SE, Williams M, Benson RBJ. 2017. Virtual reconstruction of the endocranial anatomy of the early Jurassic marine crocodylomorph Pelagosaurus typus (Thalattosuchia). PeerJ 5:e3225. DOI 10.7717/peerj.3225.

Pol D, Gasparini Z. 2009. Skull anatomy of Dakosaurus andiniensis (Thalattosuchia:

Crocodylomorpha) and the phylogenetic position of Thalattosuchia. Journal of Systematic Palaeontology 7:163-197. DOI 10.1017/S1477201908002605.

Pol D, Nascimento PM, Carvalho AB, Riccomini C, Pires-Domingues RA, Zaher H. 2014. A new notosuchian from the Late Cretaceous of Brazil and the phylogeny of advanced notosuchians. PLOS ONE 9:e93105. DOI 10.1371/journal.pone.0093105

Pol D, Rauhut OWM, Lecuona A, Leardi JM, Xu X, Clark JM. 2013. A new fossil from the Jurassic of Patagonia reveals the early basicranial evolution and the origins of Crocodyliformes. Biological Reviews 88:862-872. DOI: 10.1111/brv.12030.

Porter WR, Sedlmayr JC, Witmer LM. 2016. Vascular patterns in the heads of crocodilians: blood vessels and sites of thermal exchange. Journal of Anatomy 229:800-824. DOI 10.1111/joa.12539.

SedImayr JC. 2002. Anatomy, evolution, and functional significance of cephalic vasculature in Archosauria. PhD Thesis, Ohio University. 
1299 Soto-Acuña S, Otero RA, Rubilar-Rogers D. 2012. Un nuevo ejemplar de Metriorhynchus

1300 casamiquelai Gasparini y Chong, 1977 (Crocodylomorpha: Thalattosuchia) del

1301

1302

Caloviano de Sierra de Moreno, Región de Antofagasta. [XIII Congreso Geológico Chileno, Antofagasta]:755-757.

1303

1304

Tarsitano SF. 1985. Cranial metamorphosis and the origin of the Eusuchia. Neues Jahrbuch für Geologie und Paläontologie 170:27-44.

1305

Walker AD. 1990. A revision of Sphenosuchus acutus Haughton, a crocodylomorph reptile from the Elliot Formation (late Triassic or early Jurassic) of South Africa. Philosophical Transactions of the Royal Society of London B 330:1-120.

Westphal F. 1962. Die Krokodilier des deutschen und englischen oberen Lias. Palaeontographica A 118:23-118.

Wharton DS. 2000. An enlarged endocranial venous system in Steneosaurus pictaviensis

(Crocodylia: Thalattosuchia) from the Upper Jurassic of Les Lourdines. France. Comptes Rendus de l'Académie des Sciences-Series IIA-Earth and Planetary Science 331:221-

Wilberg E. 2015a. A new metriorhynchoid (Crocodylomorpha, Thalattosuchia) from the Middle position of Thalattosuchia (Crocodylomorpha) and the origin of crocodyliformes. 
1321 Witmer LM, Ridgely RC, Dufeau DL, Semones MC. 2008. Using CT to peer into the past: 3D

1322

1323

1324

1325

1326

1327

1328

1329

1330

1331

1332

1333

1334

1335

1336

1337

1338

1339

1340

1341

1342

1343

visualization of the brain and ear regions of birds, crocodiles and nonavian dinosaurs. In:

Endo H, Frey R, eds. Anatomical imaging: towards a new morphology. Berlin: Springer, 67-87.

Wu X-C, Chatterjee S. 1993. Dibothrosuchus elaphros, a crocodylomorph from the Lower Jurassic of China and the phylogeny of the Sphenosuchia. Journalof Vertebrate Paleontology 13:58-89. DOI 10.1080/02724634.1993.10011488.

Young MT, Andrade MB, Etches S, Beatty BL. 2013. A new metriorhynchid crocodylomorph from the Lower Kimmeridge Clay Formation (Late Jurassic) of England, with implications for the evolution of dermatocranium ornamentation in Geosaurini. Zoological Journal of the Linnean Society 169:820-848.

Young MT, Brusatte SL, Andrade MB, Desojo JB, Beatty BL, Steel L, Fernández MS, Sakamoto M, Ruiz-Omenaca JI, Schoch RR. 2012. The cranial osteology and feeding ecology of the metriorhynchid crocodylomorph genera Dakosaurus and Plesiosuchus from the Late Jurassic of Europe. PLoS ONE 7:e44985. DOI 10.1371/JOURNAL.PONE.0044985.

Young MT, Brusatte SL, Ruta M, Andrade MB. 2010. The evolution of Metriorhynchoidea (Mesoeucrocodylia, Thalattosuchia): an integrated approach using geometrics morphometrics, analysis of disparity and biomechanics. Zoological Journal of the Linnean Society 158:801-859. DOI 10.1111/j.1096-3642.2009.00571.x.

Young MT, Hastings AK, Allain R, Smith TJ. 2017. Revision of the enigmatic crocodyliform Elosuchus felixi de Lapparent de Broin, 2002 from the Lower-Upper Cretaceous boundary of Niger: potential evidence for an early origin of the clade Dyrosauridae. 


\section{Figure 1}

Braincase of Steneosaurus bollensis (BSPG 1984 I258).

In (A) dorsal; (B) ventral; (C) right anterolateral; and (D) posterior views. Abbreviations: bo, basioccipital; bs, basisphenoid; cf, carotid foramen; cr.B, crest B; fm, foramen magnum; fr, frontal; fVg, foramen for the trigeminal ganglion; Ipf, lateral pharyngeal foramen; It, laterosphenoid; met, metotic foramen; mpf, median pharyngeal foramen; ot, otoccipital; pa, parietal; pro, prootic; pt, pterygoid; q, quadrate; XII, hypoglossal foramen. Dotted white line in (C) shows laterosphenoid-prootic suture, continuous lines show the trigeminal foramen and fossa. Scale bars equal $5 \mathrm{~cm}$. 

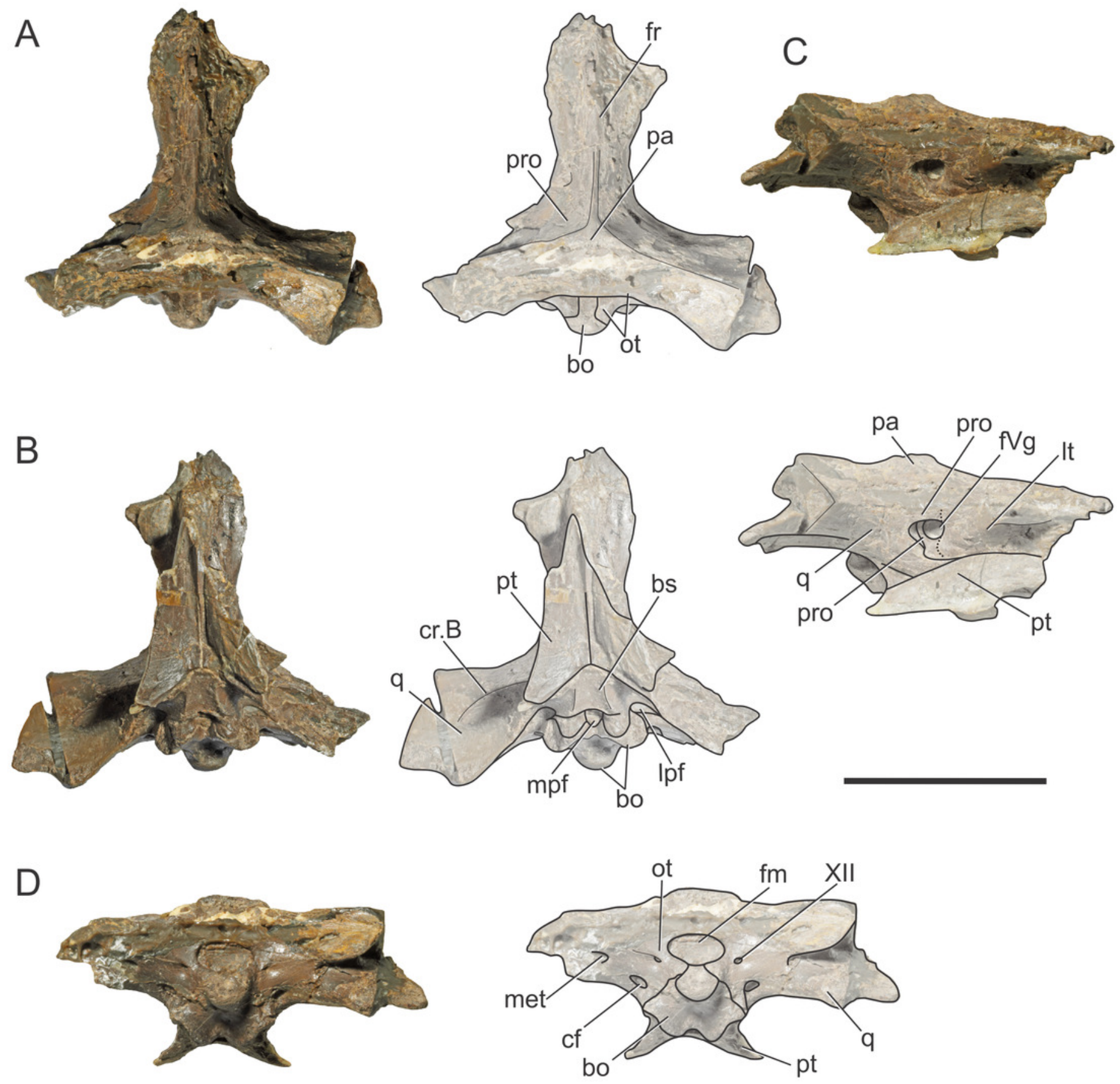


\section{Figure 2}

Reconstruction of the braincase of Steneosaurus bollensis (BSPG 1984 I258).

In (A) dorsal; (B) ventral; (C) right lateral; and (D) posterior views. Abbreviations: bo, basioccipital; bs, basisphenoid; cf, carotid foramen; cr.B, crest B; fm, foramen magnum; fr, frontal; fVg, foramen for the trigeminal ganglion; Ipf, lateral pharyngeal foramen; It, laterosphenoid; mec, middle ear cavity; mpf, median pharyngeal foramen; ot, otoccipital; pa, parietal; pro, prootic; pt, pterygoid; q, quadrate; III, oculomotor foramen; XII, hypoglossal foramen. Scale bar equals $5 \mathrm{~cm}$.
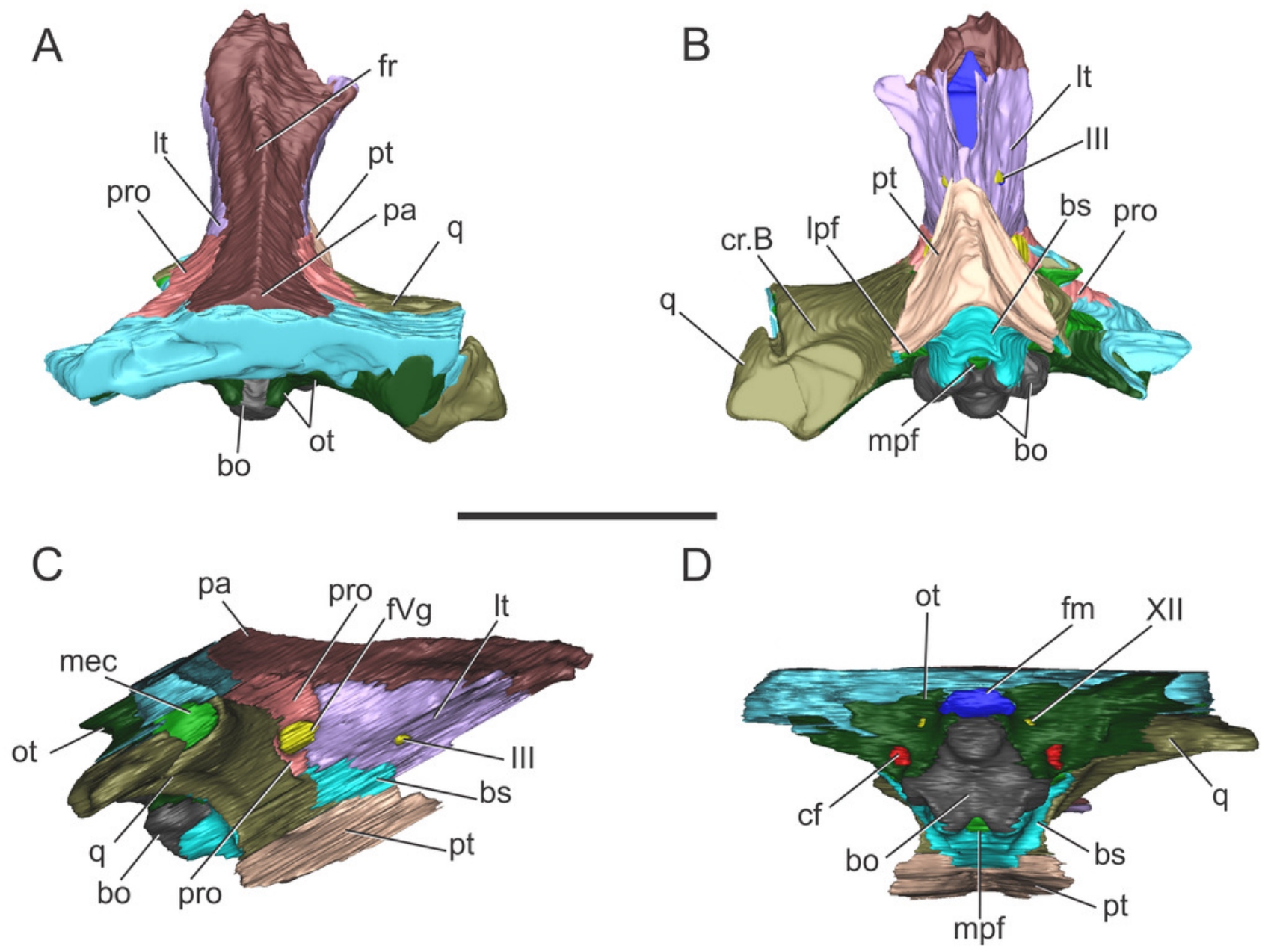


\section{Figure 3}

Endocranial anatomy of Steneosaurus bollensis (BSPG 1984 I258).

In (A-B) lateral; (C-D) dorsal; (E-F) ventral; and (G-H) posterior views. Abbreviations: BOd, basioccipital diverticulum; BSd, basisphenoid diverticulum; ch, cerebral hemisphere; cmcv, caudal middle cerebral vein; dvs, dorsal venous sinus; el, endosseous labyrinth of the inner ear; ic, internal carotid artery; OTd, otoccipital diverticulum; pf, pituitary; ?PTd, ?pterygoid diverticulum; PTt, pharyngotympanic tube; rmcv, rostral middle cerebral vein; TO/ST, temporo-orbital/stapedial vein; Vg, trigeminal ganglion; III, VI, VII, IX-XI, XII, cranial nerves. Scale bars equal $5 \mathrm{~cm}$. 

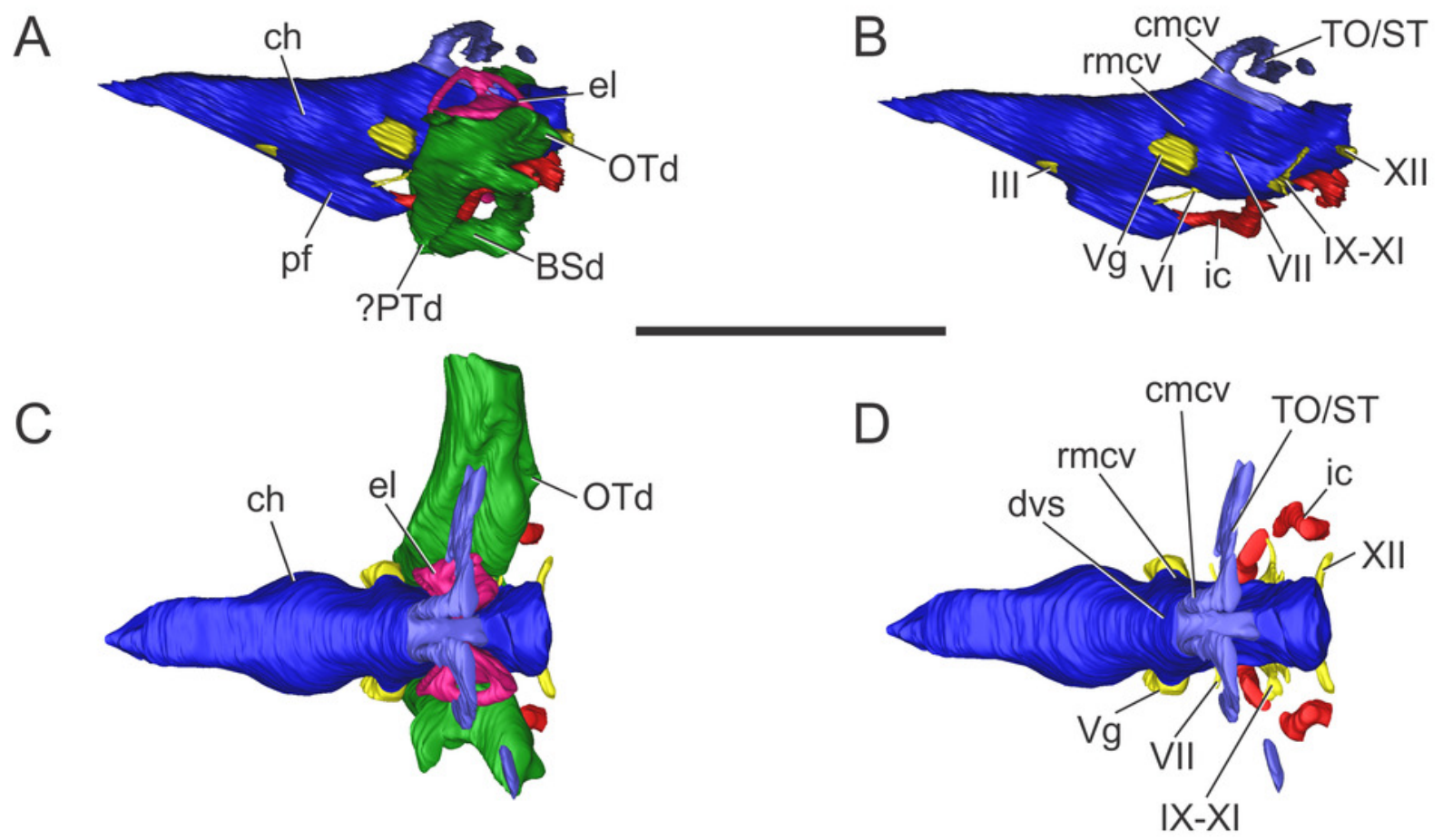

$E$

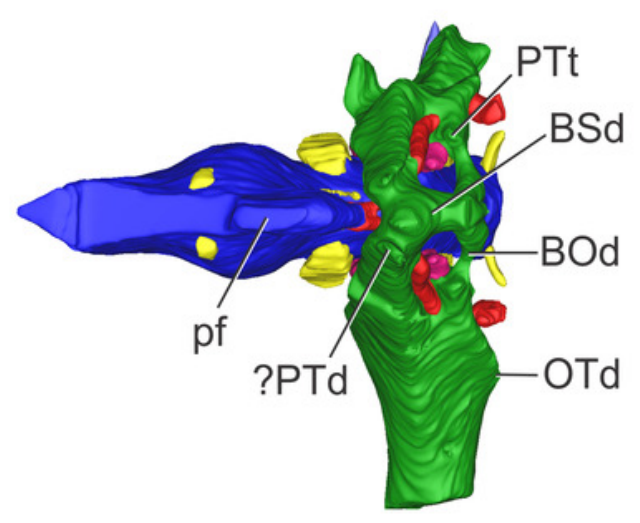

F

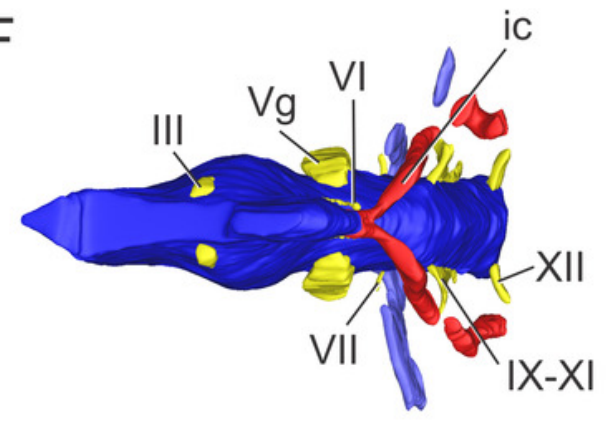

G
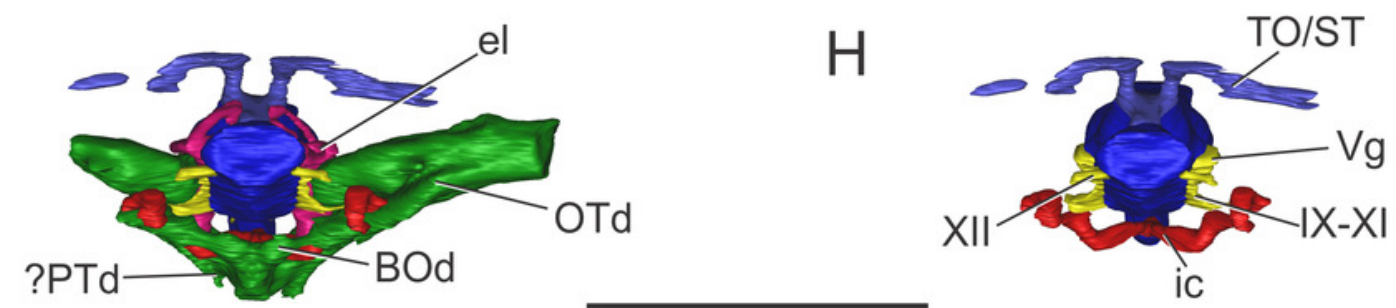


\section{Figure 4}

Left endosseous labyrinth of Steneosaurus bollensis (BSPG 1984 1258).

In (A) anterior; (B) lateral; (C) posterior; (D) posterior; and (E) dorsal views. Abbreviations: asc, anterior semicircular canal; cc, common crus; cd, cochlear duct; Isc, lateral semicircular canal; psc, posterior semicircular canal. Scale bar equals $1 \mathrm{~cm}$.

A

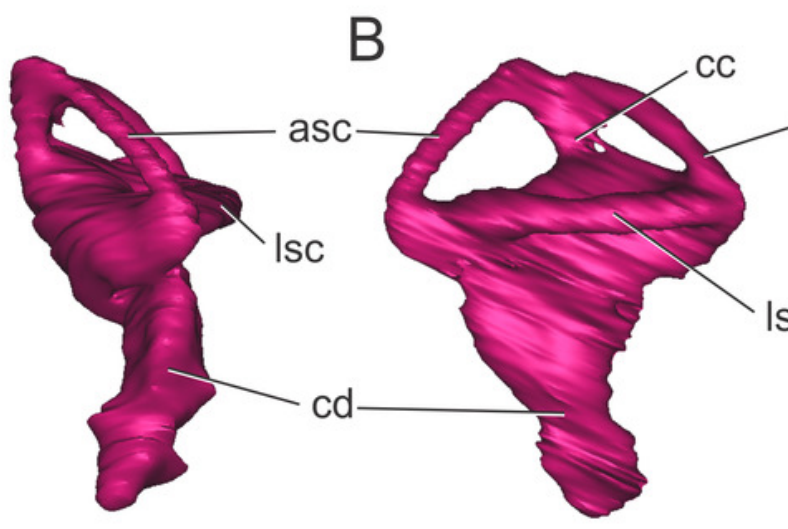

C

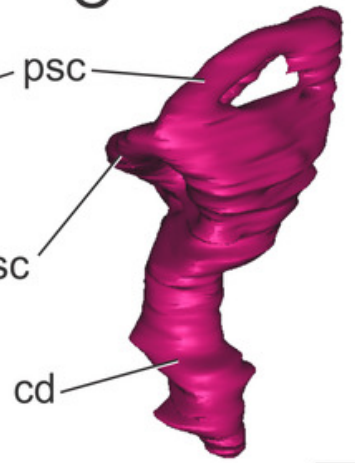

$\mathrm{D}$

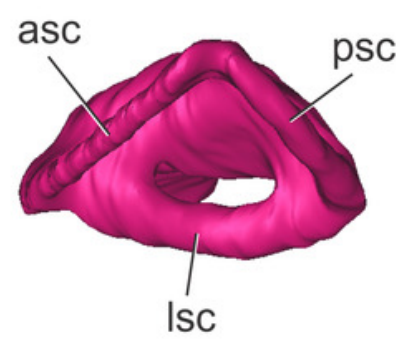




\section{Figure 5}

Braincase of Cricosaurus araucanensis (MLP 72-IV-7-1).

In (A) dorsal; (B) ventral; (C) posterior views. Abbreviations: bo, basioccipital; bs, basisphenoid; cf, carotid foramen; cq, cranioquadrate foramen; cr.B, crest B; fm, foramen magnum; fr, frontal; It, laterosphenoid; mpf, medial pharyngeal foramen; ot, otoccipital; pa, parietal; pfr, prefrontal; pl, palatine; po, postorbital; pro, prootic; pt, pterygoid; q, quadrate; so, supraoccipital; sq, squamosal; IX-XI, XII, foramina for cranial nerves. Scale bars equal 5 $\mathrm{cm}$. 

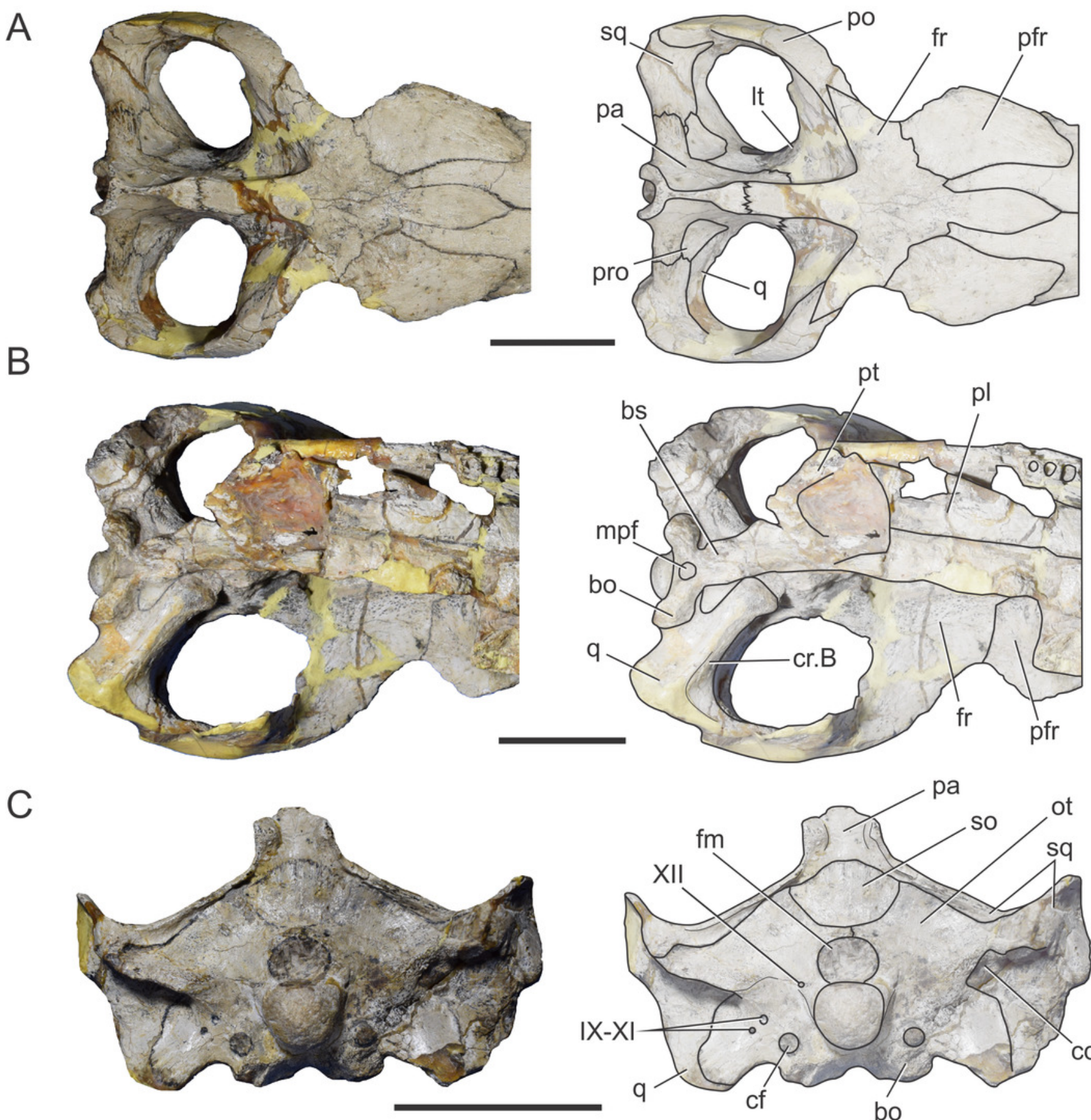

C

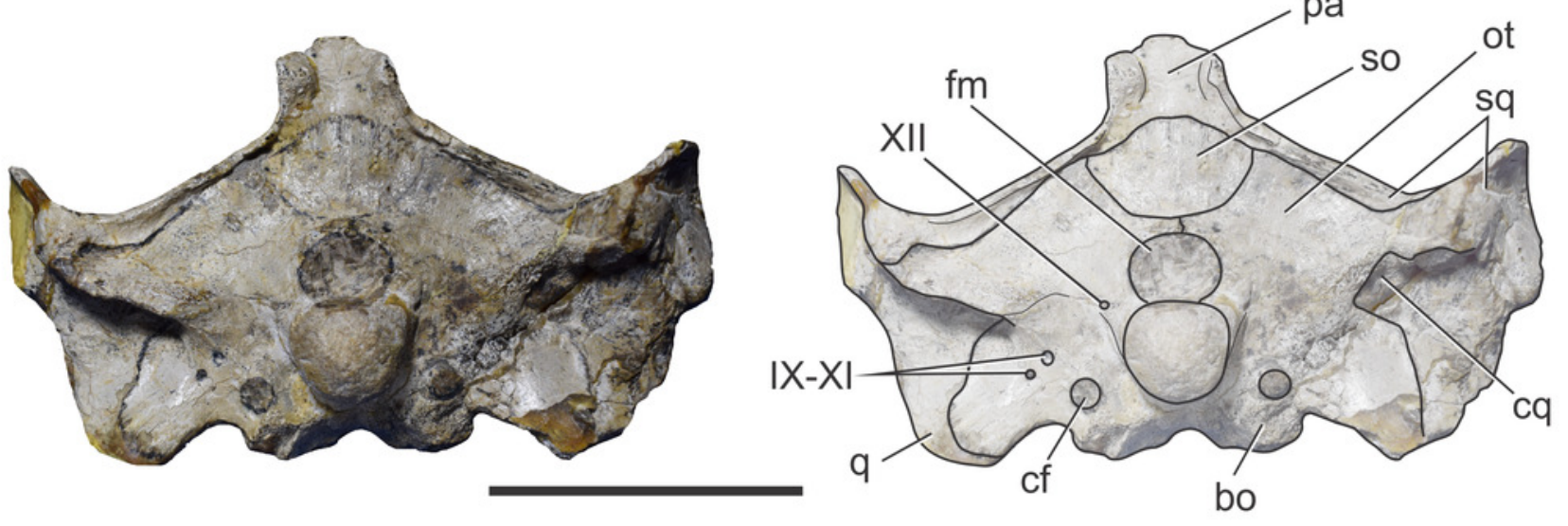




\section{Figure 6}

Braincase of Cricosaurus araucanensis (MLP 72-IV-7-1).

In (A) left dorsolateral; (B) left ventrolateral; and (C) left ventrolateral views. Abbreviations:

$\mathrm{fr}$, frontal; $\mathrm{fVg}$, foramen for the trigeminal ganglion; $\mathrm{gV}_{1}$, groove for the ophthalmic branch of the trigeminal nerve; $\mathrm{gV}_{2}$, groove for the maxillary branch of the trigeminal nerve; It, laterosphenoid; pa, parietal; po, postorbital; pro, prootic; pt, pterygoid; q, quadrate; sq, squamosal; tof, temporo-orbital foramen. The white circle on (A) marks the blood vessel infillings that cover the cerebral hemispheres. Scale bars equal $2 \mathrm{~cm}$.

A
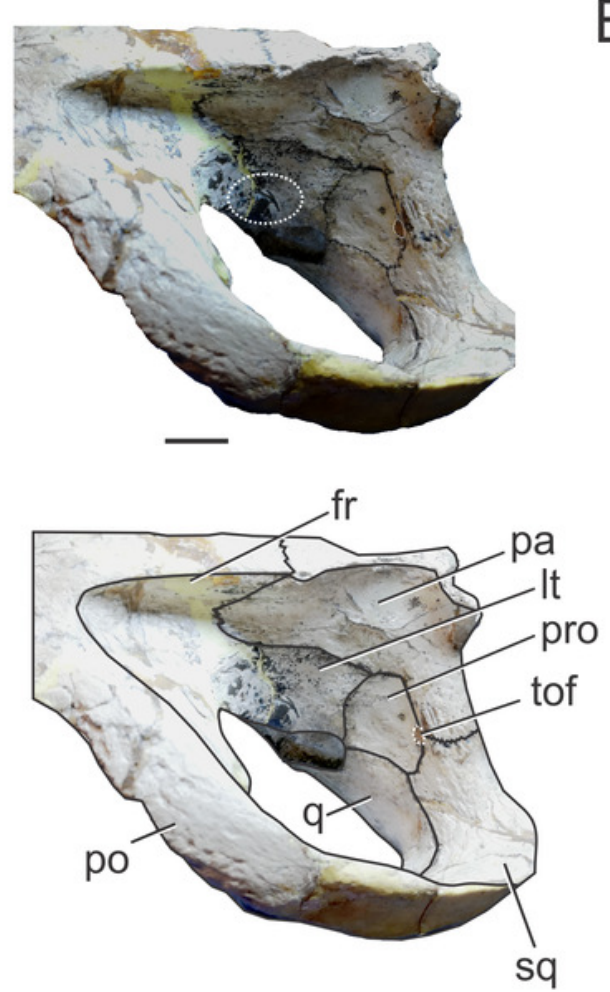

B
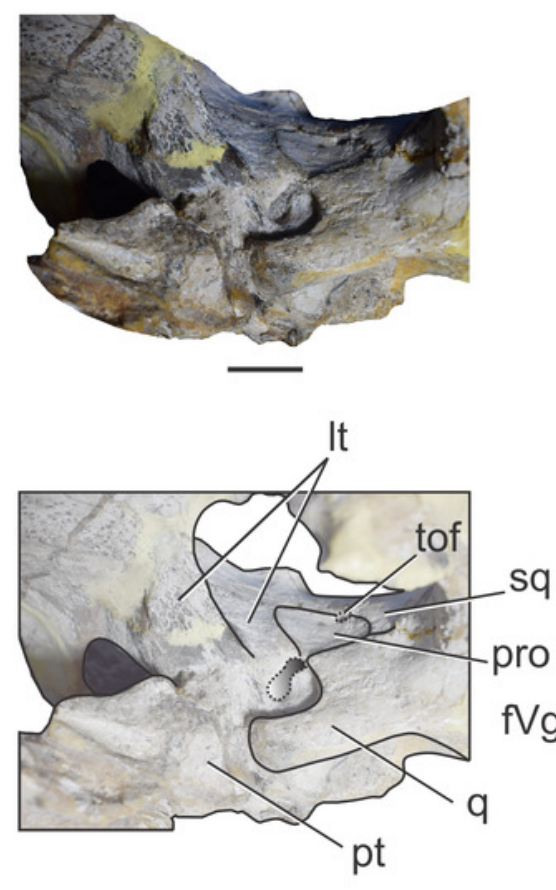

C
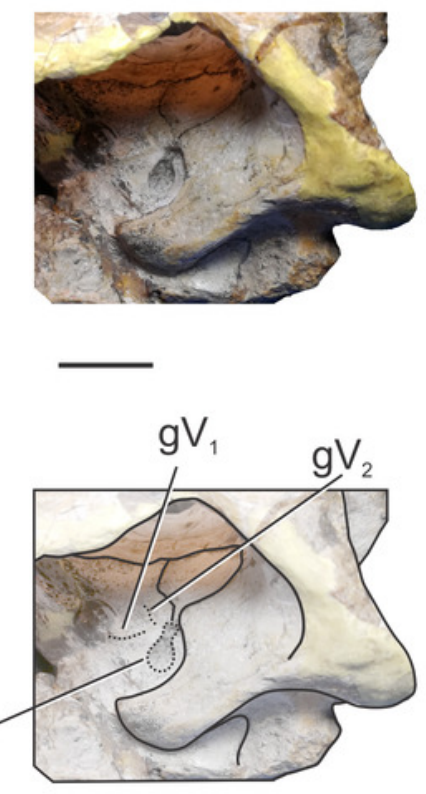


\section{Figure 7}

Endocranial anatomy of Cricosaurus araucanensis (MLP 72-IV-7-1).

In (A-B) lateral; (C-D), dorsal; (E-F), ventral; and (G-H), posterior views. Abbreviations: BSd, basisphenoid diverticulum; ch, cerebral hemisphere; cmcv, caudal middle cerebral vein; cqp, cranioquadrate passage; dvs, dorsal venous sinus; el, endosseous labyrinth of the inner ear; ETr, recessus epitubaricum; ic, internal carotid artery; oa, orbital artery; olt, olfactory tract; OTd, otoccipital diverticulum; pf, pituitary fossa; rmcv, rostral middle cerebral vein; TO/ST, temporo-orbital/stapedial vein; Vg, trigeminal ganglion; II, IV, cranial nerves. Scale bar equals $10 \mathrm{~cm}$. 

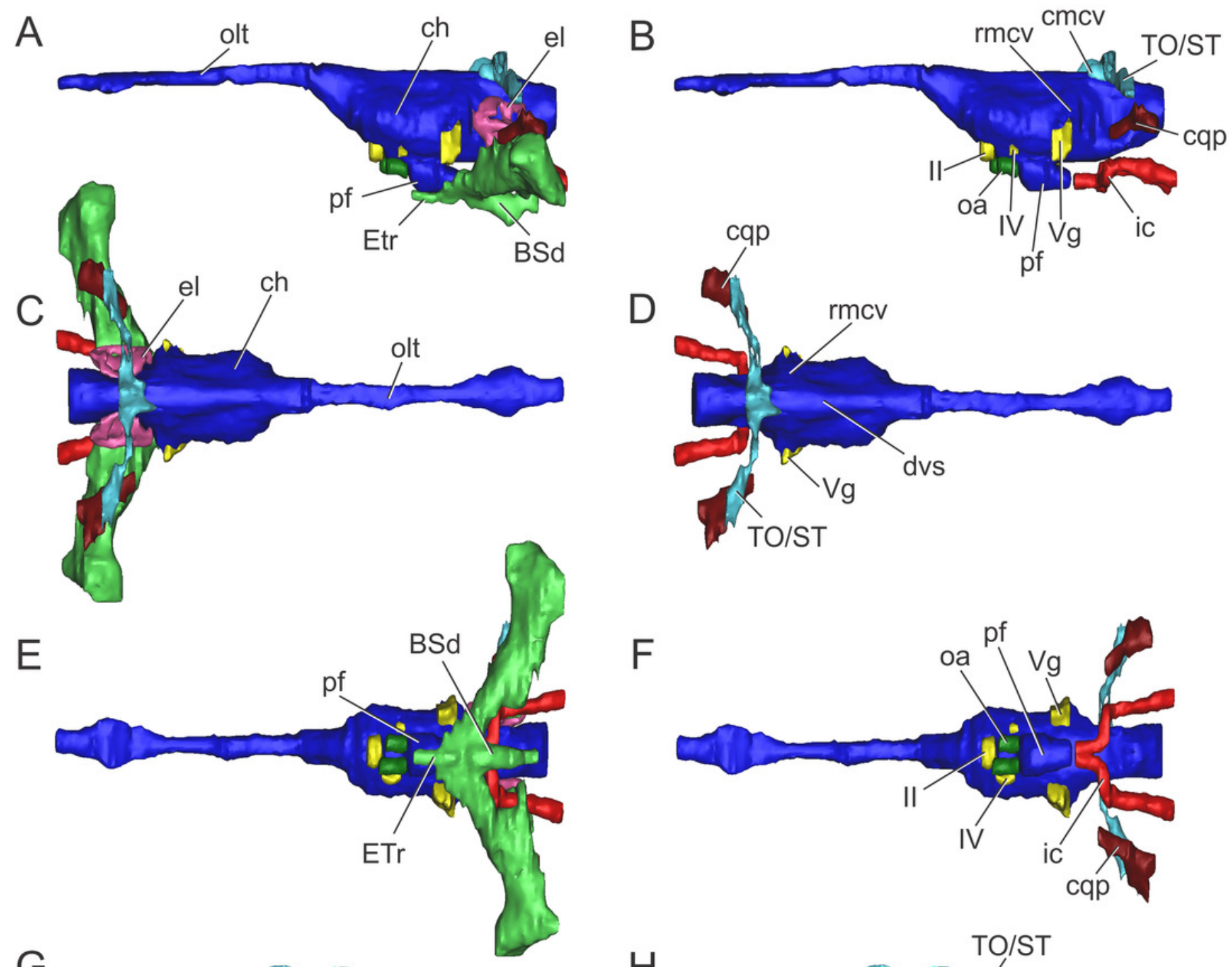

G

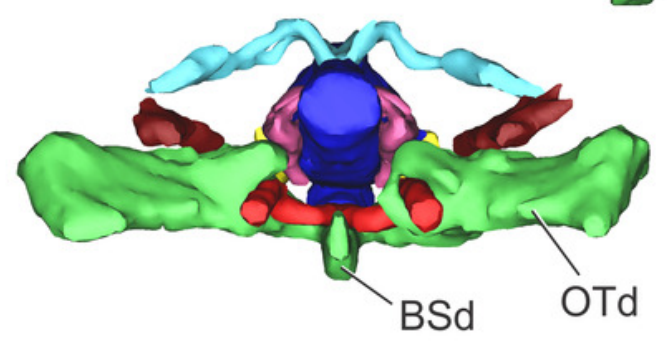

$\mathrm{H}$

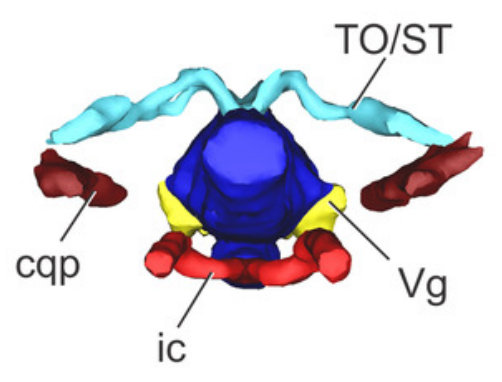




\section{Figure 8}

Left endosseous labyrinth of Cricosaurus araucanensis (MLP 72-IV-7-1).

In (A) anterior; (B) lateral; (C) posterior; and (D) dorsal views. Abbreviations: asc, anterior semicircular canal; cc, common crus; cd, cochlear duct; Isc, lateral semicircular canal; psc, posterior semicircular canal. Scale bar equals $1 \mathrm{~cm}$.

A

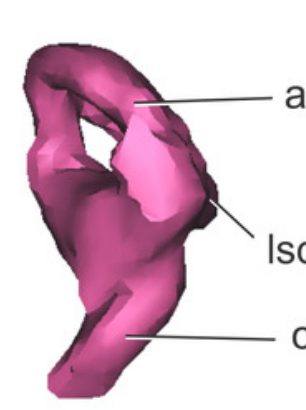

$\mathrm{B}$

$B$

$\longrightarrow \mathrm{Cc}$

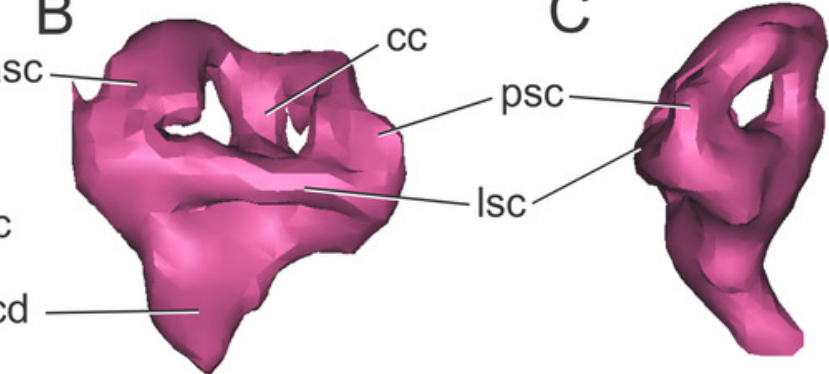

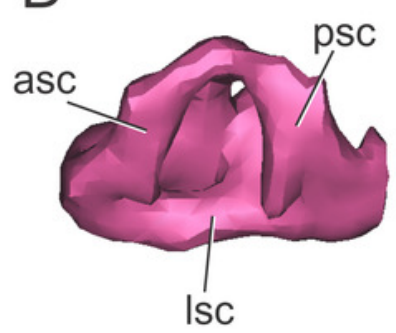




\section{Figure 9}

Braincase and endocranial features of some crocodylomorphs displayed on a phylogenetic framework (based on Pol et al., 2014).

Endocasts were redrawn from the following sources (from top): Pholidosaurus mereyi (MB.R.2027), Steneosaurus bollensis (BSPG 1984 1258), Pelagosaurus typus (Dufeau, 2011), Cricosaurus araucanensis (MLP 72-IV-7-1); Gavialis gangeticus (Bona, Paulina Carabajal \& Gasparini, 2017), Crocodylus johnstoni (Witmer et al., 2008), Simosuchus clarki (Kley et al., 2010), Sebecus icaeorhinus (Colbert, 1946a). Synapomorphies and putative synapomorphies are plotted on the cladogram (see reference chart). An $\mathrm{x}$ on the symbol represents a reversion on that character. Not to scale. 


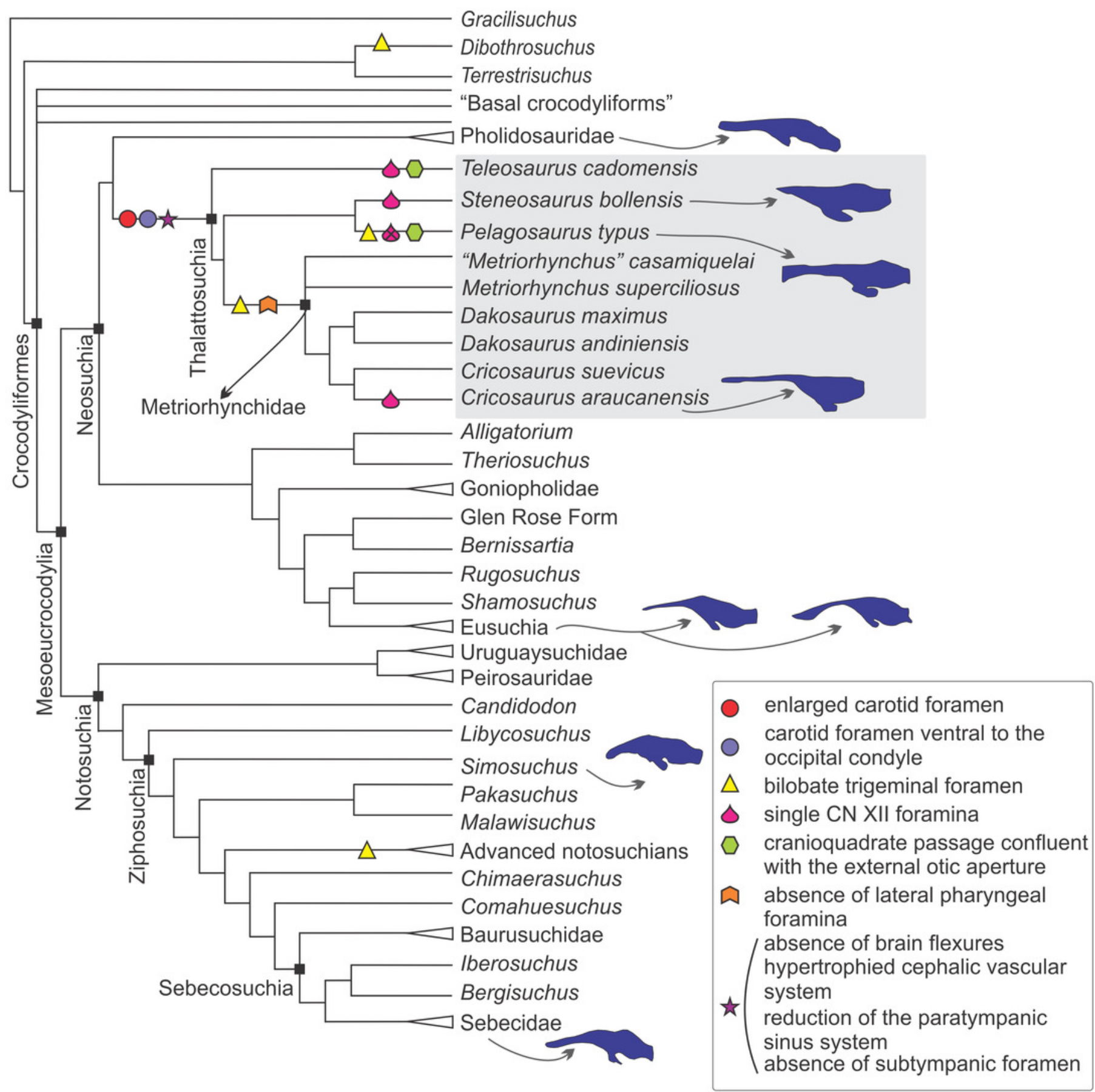




\section{Figure 10}

Braincase and endocranial features of some crocodylomorphs displayed on a phylogenetic framework (based on Young et al., 2017).

Endocasts were redrawn from the following sources (from top): Sebecus icaeorhinus (Colbert, 1946a); Gavialis gangeticus (Bona, Paulina Carabajal \& Gasparini, 2017), Crocodylus johnstoni (Witmer et al., 2008), Pholidosaurus mereyi (MB.R.2027), Steneosaurus bollensis (BSPG 1984 1258), Pelagosaurus typus (Dufeau, 2011), Cricosaurus araucanensis (MLP 72-IV7-1); "Metriorhynchus" cf. westermanni (MDA 2). Synapomorphies and putative synapomorphies are plotted on the cladogram (see reference chart). An $\mathrm{x}$ on the symbol represents a reversion on that character. Not to scale 


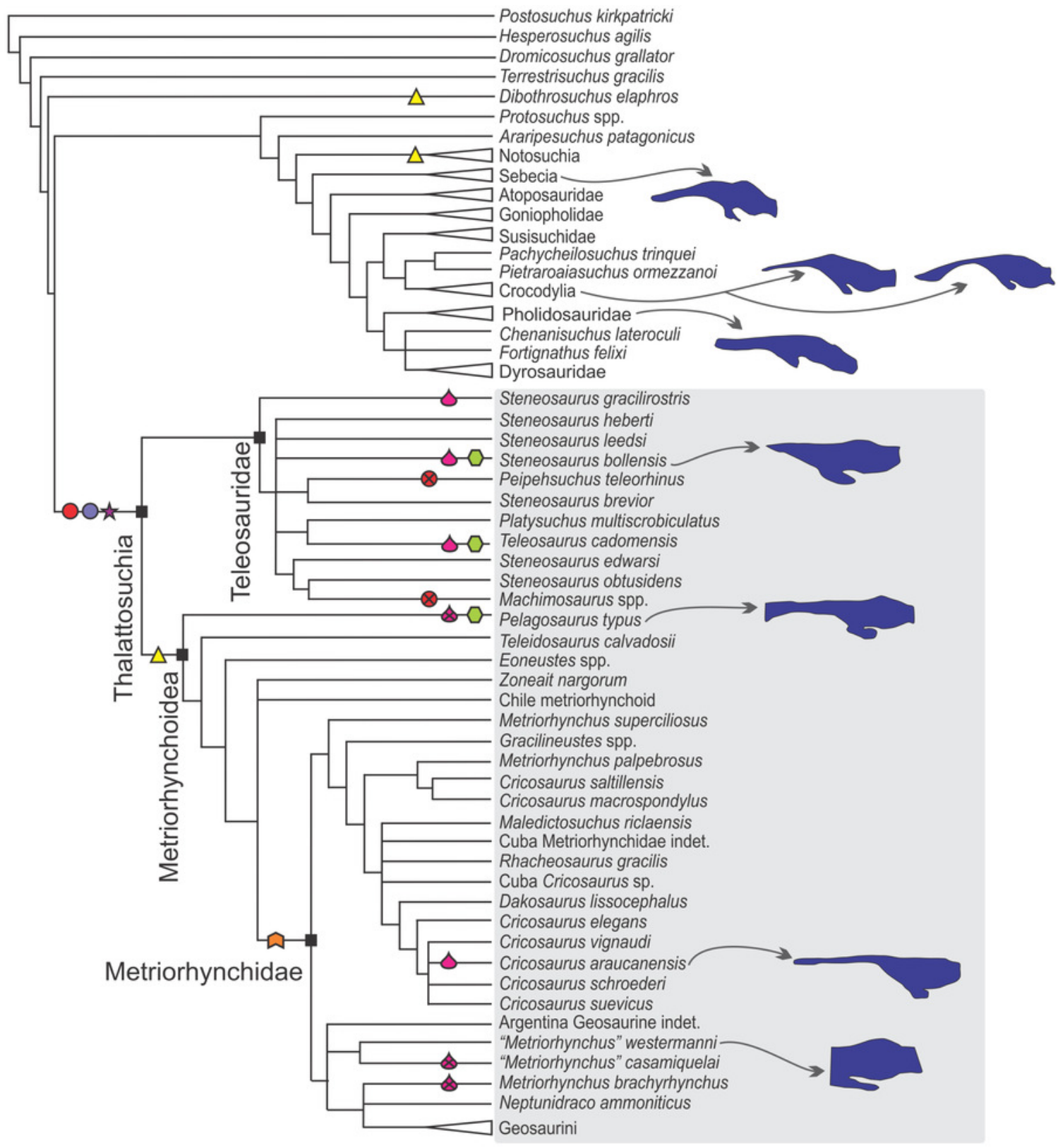

- enlarged carotid foramen

carotid foramen ventral to the occipital condyle $\Delta$ bilobate trigeminal foramen single CN XII foramen

cranioquadrate passage confluent

with the external otic aperture

๑ absence of lateral pharyngeal foramina /absence of brain flexures

$\downarrow$ ( $\begin{aligned} & \text { hypertrophied cephalic vascular system } \\ & \text { reduction of the paratympanic sinus system } \\ & \text { absence of subtympanic foramen }\end{aligned}$ 